\title{
A Modified RBF Neuro-Sliding Mode Control Technique for a Grid Connected PMSG Based Variable Speed Wind Energy Conversion System
}

\author{
Rostand Marc Douanla, ${ }^{1,2}$ Godpromesse Kenné (i), 1 \\ François Béceau Pelap ${ }^{D},{ }^{3}$ and Armel Simo Fotso ${ }^{1,2}$ \\ ${ }^{1}$ Unité de Recherche d'Automatique et d'Informatique Appliquée (LAIA), Département de Génie Électrique, \\ IUT FOTSO Victor Bandjoun, Université de Dschang, BP 134, Bandjoun, Cameroon \\ ${ }^{2}$ Unité de Recherche de Matière Condensée, d'Electronique et de Traitement du Signal (LAMACETS), \\ Département de Physique, Université de Dschang, BP 69, Dschang, Cameroon \\ ${ }^{3}$ Unité de Recherche de Mécanique et de Modélisation des Systèmes Physiques (L2MSP), Département de Physique, \\ Université de Dschang, BP 69, Dschang, Cameroon
}

Correspondence should be addressed to Godpromesse Kenné; godpromesse@gmail.com

Received 21 May 2018; Revised 26 August 2018; Accepted 4 September 2018; Published 1 October 2018

Academic Editor: Daniela Proto

Copyright (C) 2018 Rostand Marc Douanla et al. This is an open access article distributed under the Creative Commons Attribution License, which permits unrestricted use, distribution, and reproduction in any medium, provided the original work is properly cited.

\begin{abstract}
A modified control scheme based on the combination of online trained neural network and sliding mode techniques is proposed to enhance maximum power extraction for a grid connected permanent magnet synchronous generator (PMSG) wind turbine system. The proposed control method does not need the knowledge of the uncertainty bounds nor the exact model of the nonlinear system. Since the neural network is trained online, the time to estimate good weights can affect the dynamic performance of the process during the startup phase. Therefore an appropriate way to smoothly and explicitly accelerate the neural network rate of convergence during the startup phase is proposed. Furthermore, a flexible grid side voltage source converter control structure which can handle both grid connected and standalone modes based on conventional proportional integral (PI) control method is presented. Simulations are done in Matlab/Simulink environment to verify the effectiveness and assess the performance of the proposed controller. The results analysis shows the superiority of the proposed RBF neuro-sliding mode controller compared to a nonlinear controller based on sliding mode control method when the system undergoes parameter uncertainties.
\end{abstract}

\section{Introduction}

In recent years, a new challenge that seeks to reduce the effects of climate change has emerged in the world energy production domain. The exploitation of renewable energy sources has been intensified so as to tackle the growing energy demand with reduced environmental impact. Wind energy source, as a sustainable and renewable resource, has gained more interest for electrical power generation [1]. Wind energy conversion systems (WECSs) can be divided into two categories: fixed speed and variable speed. Fixed speed wind generators are directly connected to the electrical network but have limited controllability and range of operation [2].
Variable speed wind turbines (WTs) although equipped with additional components bring more advantages such as maximum power point tracking (MPPT) control strategy, increased power capture, and improved power quality [3]. The captured electrical energy can be injected into the utility grid or used to power up standalone loads. The electrical generator involved in the variable wind conversion process can be interfaced to the load by means of different topologies of controlled power electronic converters $[4,5]$.

Various investigations on wind turbine generators have shown that permanent magnet synchronous generator (PMSG) has many advantages compared to other kinds of electrical machines $[6,7]$ and therefore becomes an attractive 
choice for variable speed wind turbines. Meanwhile, the PMSG is a nonlinear dynamic and highly coupled system. In addition, the PMSG is subjected to many disturbances including change in wind speed and parameter uncertainties such as variations in stator resistance, stator inductance, rotor flux, and rotor inertia during operation. Hence, in order to tap efficiently power from PMSG based WT, it is important to take into consideration the above disturbances in the control design.

Linear controllers [8-14] have been studied and implemented. But the reduced range of operating points and poor robustness of these controllers with respect to machine uncertainties are their main limitations. Optimal tuning of control parameters for PMSG WECS using democratic joint operation algorithm has been reported in [15] to boost the performance of a linear controller. Meanwhile an alternative way to cope efficiently with the nonlinear nature and varying operation conditions of PMSG WECS is to exploit nonlinear control designs. Accordingly feedback [16, 17] and sliding mode [18-25] techniques have been successfully processed. An association of passivity theory with sliding mode control was proposed in [26] to remove the PMSG WECS nonlinearities and cope with various uncertainties. However, the implementation of the above control algorithms required the knowledge of the mathematical model of the plant which is not accurate due to various assumptions considered. In addition, the knowledge of the upper limit of the system uncertainties, including parametric variations and external disturbances, is assumed. But the difficulty to obtain the exact system uncertainties bound in practical application may lead to unsatisfactory global control performance.

In searching appropriate solutions to the aforementioned shortcomings, artificial neural network (NN) control approaches have been explored. NNs are considered to be powerful tools for identification/nonlinear control by imitating cognitive expertise of the human [27-30], thanks to their self-learning abilities and capabilities to approximate nonlinear functions. Some results from the application of NN based control schemes for PMSG WECSs can be found in [31-34]. In [31], an online learning modified recurrent Elman NN control method is designed for a standalone PMSG WECS with practical implementation. An estimation algorithm is developed to observe the upper limit of the network approximation error. This estimation helped to improve the dynamic performance of the controller. In [32], online trained wavelet recurrent NN control method to improve the transient performance of a standalone PMSG WT has been reported and some experimental results were provided. The approaches in $[31,32]$ require extra memory to store previous information and high number of neurones which in turn induces large computation time. Another fact is that the total efficiency of the controlled PMSG WECS is limited since the MPPT algorithm, which is essential for variable speed WTs, was not addressed. In [33], an adaptive RBF NN control strategy is adopted to achieve tip speed ratio MPPT control of a PMSG WT with experimental results. The NN is trained offline. The parameters of the RBF NN are adjusted using a gradient method coupled to a modified particle swarm optimization algorithm. But the difficulty to obtain offline a training pattern which matches the exact behaviour of the closed loop system can hinder the performance of this scheme. In [34], sliding mode RBF NN control is applied to extract maximum power from PMSG WT. Simulation results demonstrated the robustness of the proposed method against wind speed variations. Nevertheless, the last two control methods assumed that the uncertainties of the system lie within a known boundaries. The main contributions of this paper can be summarized as follows:

(i) A new control design of NN controller to tap maximum power from a grid connected PMSG wind turbine is investigated.

(ii) Online trained (as opposed to offline trained methods, e.g., [33]) RBF neuro-sliding mode controller is selected to benefit from the simple structure and the properties of approximation capability of RBF NN and the robustness feature of sliding mode.

(iii) An estimation of the upper limit of the system uncertainty bound which is not obtainable in practice is provided (as opposed to some existing works [33, 34]).

(iv) A solution to reduce the control effort and accelerate the rate of convergence of the network during the startup phase (as opposed to the method in [30]) is proposed.

(v) A PI control scheme for the grid side which is able to handle both grid connected and stand modes of operation is proposed.

The remainder of this paper is organized as follows. Section 2 focuses on the system modeling. In Section 3, the proposed hybrid control development is presented and the GSC control design is provided in Section 4. Computer simulations using a nonlinear controller based on sliding mode control method and the proposed sliding neural control approach are reported in Section 5. The conclusions of the paper are drawn up in Section 6.

\section{PMSG WECS Modeling}

Figure 1 presents an overview of the grid connected PMSG WECS under analysis. A wind turbine rotor is coupled to a PMSG shaft via a gearbox. The PMSG is controlled through a PWM machine side converter (MSC) to enhance MPPT. An electronic load controller (ELC), composed of a single switch PWM dc-to-dc converter feeding an electronic load, is used to provide a fixed dc voltage needed for PWM grid side converter (GSC) operation. The electronic load, working in a constant voltage mode, is designed such that when the duty cycle of the dc-to-dc converter is unity (during fault or over generation), it should consume the maximum output power of the generator. A LCL filter is introduced to improve the quality of the power injected into the local AC load or the grid by lessening the harmonics produced by the GSC switching effects. A circuit breaker is used in case of grid connected/standalone transition. 


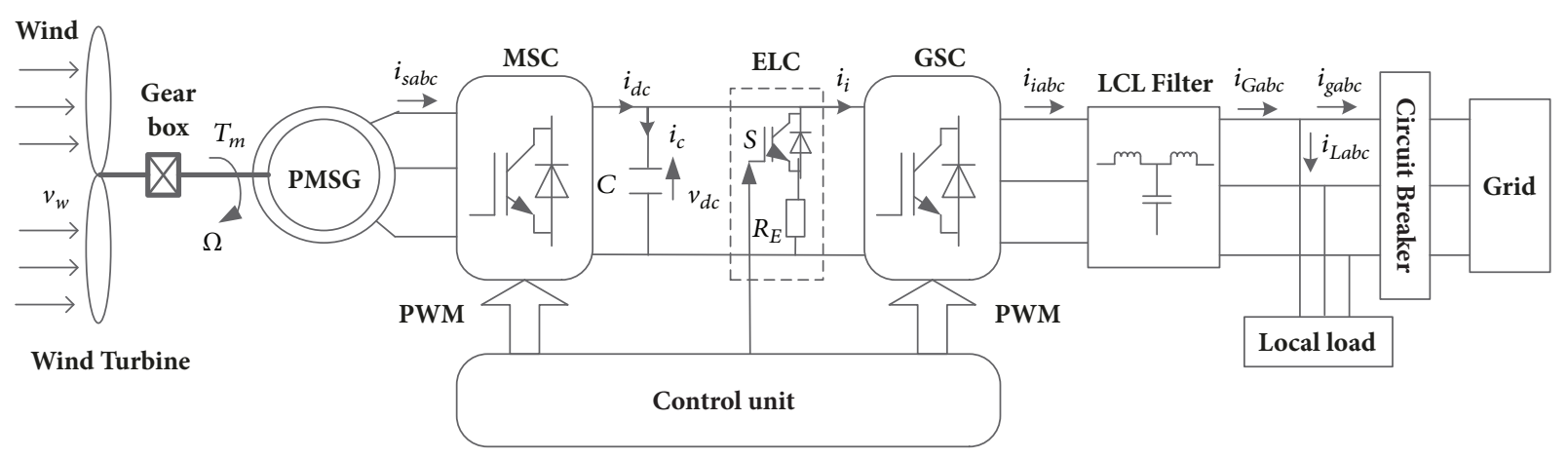

FIGURE 1: Control system diagram.

2.1. Turbine Modeling. The mechanical power $P_{m}$ extracted by the WT from the kinetic energy of the wind is expressed in terms of the air density $\rho$, the area swept by the blades $\pi r^{2}$ ( $r$ is the blade radius), the power coefficient $C_{p}(\zeta, \beta)$, and the wind speed $v_{w}$ as follows [35]:

$$
P_{m}=0.5 \rho \pi r^{2} C_{p}(\zeta, \beta) v_{w}^{3} .
$$

The power coefficient is a function of the tip speed ratio $\zeta$ and the blade pitch angle $\beta$ and can be stated as

$$
\begin{array}{r}
C_{p}(\zeta, \beta)=0.5176\left(\frac{116}{\zeta_{i}}-0.4 \beta-5\right) e^{-21 / \zeta_{i}}+0.0068 \zeta \\
\text { with } \frac{1}{\zeta_{i}}=\frac{1}{\zeta+0.08 \beta}-\frac{0.035}{\beta^{3}+1} .
\end{array}
$$

The tip speed ratio $\zeta$ is expressed as

$$
\begin{aligned}
& \zeta=\frac{r \Omega_{t}}{v_{w}}=\frac{r \Omega}{G v_{w}}, \\
& G=\frac{\Omega}{\Omega_{t}}=\frac{T_{t}}{T_{m}} .
\end{aligned}
$$

where $G$ represents the gearbox ratio. $\Omega_{t}$ and $T_{t}$ are rotational speed and torque developed by the turbine at the blade side of the gearbox while $\Omega$ and $T_{m}$ are the machine side shaft speed and mechanical torque, respectively. $T_{m}$ is computed by combining (1) and (3) as

$$
T_{m}=\frac{P_{m}}{\Omega}=0.5 \rho \pi r^{5} \frac{C_{p}(\zeta, \beta) \Omega^{2}}{(G \zeta)^{3}} .
$$

The turbine equation of motion referred to as the generator side of the gearbox is given by

$$
\dot{\Omega}=\frac{T_{m}}{J}-\frac{f \Omega}{J}-\frac{T_{e}}{J}
$$

with $J$ and $f$ being the total rotating parts inertia and viscous factor, respectively. $T_{e}$ is the electromagnetic torque of the generator and is defined later.

When the wind speeds belong to region $2[36,37]$, i.e., between the cut-in and the rated values, the MPPT algorithm should be enabled to increase the efficiency of the turbine captured power. Therefore the power coefficient should be kept at its maximum value $C_{p \max }$ for each wind speed in this region. This is possible if the turbine is working at the optimum tip speed ratio $\zeta_{o p t}$ which in turn leads to generator optimum speed as follows:

$$
\Omega_{o p t}=\frac{\zeta_{o p t} G v_{w}}{r}
$$

Hence the optimum power caption is achieved if the generator speed is steered to the optimum speed $\Omega^{*}=\Omega_{\text {opt }}$. This MPPT scheme, known as tip speed ratio MPPT, is adopted in the present work. Thus the target optimum power of the generator is computed as

$$
P_{\text {mopt }}=K_{o p t} \Omega_{o p t}^{3}
$$

where $K_{o p t}=0.5 \rho \pi r^{5}\left(C_{p \max } /\left(G \zeta_{o p t}\right)^{3}\right)$ is the optimal torque constant.

2.2. Modeling of PMSG Associated with MSC and dc-Link. The nonlinear dynamics of a surface mounted PMSG coupled with PWM voltage source rectifier and PWM dc-to-dc converter (see Figure 1 ) in the synchronously rotating $(d, q)$ coordinates system is described as follows [38-40]:

$$
\begin{aligned}
\dot{i}_{s d} & =-\frac{R_{s}}{L_{s}} i_{s d}+p \Omega i_{s q}-\frac{v_{s d}}{L_{s}} \\
\dot{i}_{s q} & =-\frac{R_{s}}{L_{s}} i_{s q}-p \Omega i_{s d}+\frac{p \Omega \phi_{r}}{L_{s}}-\frac{v_{s q}}{L_{s}} \\
T_{e} & =\frac{3}{2} p \phi_{r} i_{s q}, \\
P_{e} & =\frac{3 p \Omega \phi_{r} i_{s q}}{2} \\
\phi_{s d} & =L_{s} i_{s d}+\phi_{r}, \\
\phi_{s q} & =L_{s} i_{s q}
\end{aligned}
$$




$$
\begin{aligned}
& v_{s d}=S_{d} v_{d c}, \\
& v_{s q}=S_{q} v_{d c} \\
& \dot{v}_{d c}=\frac{1}{C}\left(S_{d} i_{s d}+S_{q} i_{s q}\right)-\frac{S v_{d c}}{C R_{E}}-\frac{i_{i}}{C} \\
& \dot{v}_{d c}^{2}=\frac{3 p \Omega \phi_{r} i_{s q}}{C}-\frac{2 S v_{d c}^{2}}{C R_{E}}-\frac{2 P_{i}}{C}
\end{aligned}
$$

where $i_{s d q}$ denote the stator current components and $R_{s}$ and $L_{s}$ are the stator windings resistance and inductance. $p$ is the number of pole pairs. $\phi_{s d q}$ are the stator flux components and $\phi_{r}$ is the rotor flux. $P_{e}$ is the electrical power delivered by the generator. $v_{s d q}$ are the stator voltage components while $v_{d c}$ is the voltage across the dc-link capacitor C. $R_{E}$ is the electronic load resistance. $S$ is the duty cycle of the dc-todc converter switch. $i_{i}$ and $P_{i}$ are the GSC current and active power, respectively. $S_{d q}$ state the $(a, b, c)$ to $(d, q)$ reference frame transformation of the PWM duty ratios $S_{a b c}$ of the MSC switching devices.

2.3. GSC and LCL Filter Dynamics. The mathematical model of the GSC and LCL filter in the $(d, q)$ coordinates system is expressed as follows [41]:

$$
\begin{aligned}
& L_{1} \dot{i}_{i d}=-R_{1} i_{i d}+L_{1} \omega_{g} i_{i q}+v_{i d}-v_{d} \\
& L_{1} \dot{i}_{i q}=-R_{1} i_{i q}-L_{1} \omega_{g} i_{i d}+v_{i q}-v_{q} \\
& C_{f} \dot{v}_{d}=i_{i d}-i_{G d} \\
& C_{f} \dot{v}_{q}=i_{i q}-i_{G q} \\
& L_{2} \dot{i}_{G d}=-R_{2} i_{G d}+L_{2} \omega_{g} i_{G q}+v_{d}-v_{g d} \\
& L_{2} \dot{i}_{G q}=-R_{2} i_{G q}-L_{2} \omega_{g} i_{G d}+v_{q}-v_{g q}
\end{aligned}
$$

where $i_{i d q}, v_{d q}$, and $i_{G d q}=i_{g d q}+i_{L d q}$ are inverter current, filter capacitor voltage, and grid side current components. $i_{L d q}$ and $i_{g d q}$ represent, respectively, the local AC load current and injected grid current components. $v_{i d}=S_{i d} v_{d c}$ and $v_{i q}=$ $S_{i q} v_{d c}$ denote the inverter output voltage components. $S_{i d}$ and $S_{i q}$ are the duty ratios of the GSC. $\omega_{g}$ is the angular frequency of the grid voltage. $L_{1}, L_{2}$, and $C_{f}$ denote, respectively, the LCL filter inverter side inductance, capacitance, and grid side inductance. The filter inductors have internal resistances $R_{1}$ and $R_{2}$.

\section{Proposed RBF Neuro-Sliding Mode Control Design}

The MSC, acting as voltage source rectifier, is controlled to efficiently extract the maximum power from the wind turbine while the dc-to-dc converter control task is to track the voltage across the dc-link capacitor to the desired level. It is important to regulate the dc voltage for the efficient working of the GSC. The $d$-axis current reference is set to zero in order to obtain unity power factor of the PMSG while the generator speed reference is equal to the optimal rotor speed defined earlier for MPPT.
In [30] authors proposed a combined online trained RBF neural network and sliding mode control algorithm for a class of SISO nonlinear uncertain systems. In the present study the same approach is modified and exploited. Unless otherwise specified, the proposed control development is conducted assuming the following:

(A1) The state variables as well as the system disturbances are bounded; i.e., they belong to a compact subset $\Gamma \subset \mathfrak{R}$.

(A2) The rate of change of the system parameters is slow compared to the fast dynamics of the system state variables.

(A3) The upper bound of the system uncertainties is unknown.

Before processing the proposed RBF neuro-sliding mode control scheme, let us derive each state variable to be control (i.e., $i_{s d}, \Omega$ and $v_{d c}$ ) until its control input explicitly appears and thus rearrange the $d$-axis current dynamic in (8) as

$$
\begin{aligned}
\dot{i}_{s d} & =f_{i_{s d}}+g_{i_{s d}} v_{s d}+d_{i_{s d}}(t) \\
\text { with } f_{i_{s d}} & =-\frac{R_{s}}{L_{s}} i_{s d}+p \Omega i_{s q} \\
\text { and } g_{i_{s d}} & =-\frac{1}{L_{s}} .
\end{aligned}
$$

The term $d_{i_{s d}}(t)$ has been added to represent the unknown uncertainties of the system. Since the mechanical torque is unmeasurable, replace it by its optimal expression $K_{o p t} \Omega^{2}$. Then consider the electromagnetic torque expression in (10) and derive (5) with respect to time as follows:

$$
\ddot{\Omega}=f_{\Omega}+g_{\Omega} v_{s q}+d_{\Omega}(t)
$$

$$
\text { with } \begin{aligned}
f_{\Omega}= & \frac{2 K_{o p t} \Omega-f}{J^{2}}\left(K_{o p t} \Omega^{2}-f \Omega-\frac{3 p \phi_{r} i_{s q}}{2}\right) \\
& +\frac{3 p \phi_{r}}{2 J L_{s}}\left(R_{s} i_{s q}+p \Omega L_{s} i_{s d}-p \Omega \phi_{r}\right)
\end{aligned}
$$

and $g_{\Omega}=\frac{3 p \phi_{r}}{2 J L_{s}}$

$d_{\Omega}(t)$ represents the unknown uncertainties of the system.

From (14), rewrite the dc-link voltage dynamic as $\left(u=v_{d c}^{2}\right.$ and $d_{v_{d c}}(t)$ state, respectively, the square dc voltage, and the system uncertainties):

$$
\begin{aligned}
\dot{u} & =f_{u}+g_{u} v_{u}+d_{v_{d c}}(t) \text { with } \\
f_{u} & =\frac{3 p \Omega \phi_{r}}{C} i_{s q}-\frac{2 P_{i}}{C}, \\
g_{u} & =-\frac{2}{C R_{E}}, \\
v_{u} & =S u .
\end{aligned}
$$


Now define the $\mathrm{d}$-axis current, the rotor speed, and square $\mathrm{dc}$ voltage tracking errors as $e_{i_{s d}}=i_{s d}-i_{s d}^{*}, e_{\Omega}=\Omega-\Omega^{*}$, and $e_{u}=u-u^{*}$, respectively (the reference signals are marked with $*)$. Let also the associated sliding variables be $S_{i_{s d}}, S_{\Omega}$, and $S_{u}$ such that $\left(h_{1}>0, h_{2}\right.$ and $\left.h_{3}>0\right)$

$$
\begin{aligned}
& S_{i_{s d}}=e_{i_{s d}}+h_{1} \int e_{i_{s d}} d t \\
& S_{\Omega}=\dot{e}_{\Omega}+h_{2} e_{\Omega}+h_{3} \int e_{\Omega} d t, \\
& S_{u}=e_{u} .
\end{aligned}
$$

Derive the sliding surfaces with respect to time and obtain

$$
\begin{aligned}
& \dot{S}_{i_{s d}}=f_{i_{s d}}+g_{i_{s d}} v_{s d}+d_{i_{s d}}(t)+\mu_{i_{s d}}, \\
& \dot{S}_{\Omega}=f_{\Omega}+g_{\Omega} v_{s q}+d_{\Omega}(t)+\mu_{\Omega}, \\
& \dot{S}_{\Omega}=f_{u}+g_{u} v_{u}+d_{u}(t)+\mu_{u} .
\end{aligned}
$$

with $\mu_{i_{s d}}=h_{1} e_{i_{s d}}-\dot{i}_{s d}^{*}, \mu_{\Omega}=h_{2} \dot{e}_{\Omega}+h_{3} e_{\Omega}-\ddot{\Omega}^{*}$ and $\mu_{u}=-\dot{u}^{*}$.

Consider systems (21), (23), and (25) with proposed respective controllers in (31), (32), and (33)

$$
\begin{aligned}
& v_{s d}^{*}=-\frac{1}{g_{i_{s d}}}\left(f_{i_{s d}}+\mu_{i_{s d}}+d_{i_{s d}}(t)\right)-\frac{S_{i_{s d}}}{\epsilon_{i_{s d}}}, \\
& v_{s q}^{*}=-\frac{1}{g_{\Omega}}\left(f_{\Omega}+\mu_{\Omega}+d_{\Omega}(t)\right)-\frac{S_{\Omega}}{\epsilon_{\Omega}} \\
& v_{u}^{*}=-\frac{1}{g_{u}}\left(f_{u}+\mu_{u}+d_{u}(t)\right)-\frac{S_{u}}{\epsilon_{u}}
\end{aligned}
$$

where $0<\epsilon_{i_{s d}}<1,0<\epsilon_{\Omega}<1$, and $0<\epsilon_{u}<1$ are design parameters. Thus (28), (29), and (30) become

$$
\begin{aligned}
& \dot{S}_{i_{s d}}=-\frac{S_{i_{s d}}}{\epsilon_{i_{s d}}}, \\
& \dot{S}_{\Omega}=-\frac{S_{\Omega}}{\epsilon_{\Omega}}, \\
& \dot{S}_{u}=-\frac{S_{u}}{\epsilon_{u}} .
\end{aligned}
$$

From (34), (35), and (36) one can conclude that $S_{i_{s d}}, S_{\Omega}$, and $S_{u}$ converge exponentially to 0 .

Remark 1. Considering the assumption that the functions $f_{i_{s d}}, g_{i_{s d}}, f_{\Omega}, g_{\Omega}, f_{u}$, and $g_{u}$ along with the terms $\mu_{i_{s d}}, d_{i_{s d}}(t)$, $\mu_{\Omega}, d_{\Omega}(t), \mu_{u}$, and $d_{v_{d c}}(t)$ are unknown, the controllers in (31), (32), and (33) can not be implemented in real operation condition. Consequently three sets of RBF neuro-sliding mode controllers are employed to estimate the control signals $v_{s d}^{*}, v_{s q}^{*}$, and $v_{u}^{*}$.
Remark 2 (the conditions $g_{i_{s d}}<0, g_{\Omega}>0$, and $g_{u}<0$ can be verified). Compute the proposed approximations of the desired control actions $v_{s d}^{*}, v_{s q}^{*}$, and $v_{u}^{*}$ as follows:

$$
\begin{gathered}
\widehat{v}_{s d}^{*}\left(\chi_{i_{s d}}, t\right)=\Psi\left(\chi_{i_{s d}}, \widehat{\omega}_{i_{s d}}\right)+b_{i_{s d}}(t), \\
\widehat{v}_{s q}^{*}\left(\chi_{\Omega}, t\right)=\Psi\left(\chi_{\Omega}, \widehat{\omega}_{\Omega}\right)+b_{\Omega}(t), \\
\widehat{v}_{u}^{*}\left(\chi_{u}, t\right)=\Psi\left(\chi_{u}, \widehat{\omega}_{u}\right)+b_{u}(t),
\end{gathered}
$$

where $\chi_{i_{s d}}^{T}=\left(i_{s d}, S_{i_{s d}}, S_{i_{s d}} / \epsilon_{i_{s d}}\right), \chi_{\Omega}^{T}=\left(\Omega, S_{\Omega}, S_{\Omega} / \epsilon_{\Omega}\right)$, and $\chi_{u}^{T}=\left(u, S_{u}, S_{u} / \epsilon_{u}\right)$ are the NNs input vectors. $\Psi\left(\chi_{i_{s d}}, \widehat{\omega}_{i_{s d}}\right)$, $\Psi\left(\chi_{\Omega}, \widehat{\omega}_{\Omega}\right)$, and $\Psi\left(\chi_{u}, \widehat{\omega}_{u}\right)$ denote the RBF NNs. $\widehat{\omega}_{i_{s d}}, \widehat{\omega}_{\Omega}$, and $\widehat{\omega}_{u}$ are estimations of optimal weight vectors $\omega_{i_{s d}}^{*}, \omega_{\Omega}^{*}$, and $\omega_{u}^{*}$. Bearing in mind Remark 2 , the terms $b_{i_{s d}}(t), b_{\Omega}(t)$, and $b_{u}(t)$, which help to improve the neural networks rate of convergence in the presence of uncertainties, are described as follows:

$$
\begin{gathered}
b_{i_{s d}}(t)=\widehat{\lambda}_{i_{s d}} \operatorname{sign}\left(S_{i_{s d}}\right) \\
b_{\Omega}(t)=-\hat{\lambda}_{\Omega} \operatorname{sign}\left(S_{\Omega}\right) \\
b_{u}(t)=\hat{\lambda}_{u} \operatorname{sign}\left(S_{u}\right) .
\end{gathered}
$$

$\hat{\lambda}_{i_{s d}}, \hat{\lambda}_{\Omega}$, and $\hat{\lambda}_{u}$ are estimates of the positive unknown limits of the NNs uncertainties and are computed as

$$
\begin{aligned}
& \dot{\hat{\lambda}}_{i_{s d}}= \begin{cases}\alpha_{i_{s d}}, & \text { if } S_{i_{s d}} \neq 0 \\
0, & \text { if } S_{i_{s d}}=0\end{cases} \\
& \dot{\hat{\lambda}}_{\Omega}= \begin{cases}\alpha_{\Omega}, & \text { if } S_{\Omega} \neq 0 \\
0, & \text { if } S_{\Omega}=0\end{cases} \\
& \dot{\vec{\lambda}}_{u}= \begin{cases}\alpha_{u}, & \text { if } S_{u} \neq 0 \\
0, & \text { if } S_{u}=0\end{cases}
\end{aligned}
$$

where $\alpha_{i_{s d}}, \alpha_{\Omega}, \alpha_{u}>0$ and $\hat{\lambda}_{i_{s d}}(0), \hat{\lambda}_{\Omega}(0), \hat{\lambda}_{u}(0)=0$. For $N$ number of nodes in the hidden layer, the functions $\Psi$ and $\widehat{\omega}$ are described as follows:

$$
\begin{aligned}
& \Psi\left(\chi_{x}, \widehat{\omega}_{x}\right)=\sum_{j=1}^{N} \widehat{\omega}_{x j} \psi\left(\left\|\chi_{x}-c_{x j}\right\|, v_{x j}\right) ; \\
& \widehat{\omega}_{x \jmath}=\operatorname{Proj}\left[-\left.S_{x} \frac{\partial \Psi}{\partial \omega_{x \jmath}}\right|_{\omega_{x \jmath}=\widehat{\omega}_{x j}}\right] \\
& = \begin{cases}-\left.S_{x} \frac{\partial \Psi}{\partial \omega_{x \jmath}}\right|_{\omega_{x \jmath}=\widehat{\omega}_{x \jmath}}, & \text { if }\left|\widehat{\omega}_{x \jmath}\right|<\mathfrak{R}_{\omega} \\
0, & \text { otherwise }\end{cases} \\
& x=i_{s d}, \Omega, u ; \jmath=1, \ldots, N,
\end{aligned}
$$

where $\psi=\exp \left(-\left\|\chi_{x}-c_{x_{j}}\right\|^{2} / 2 v_{x_{j}}^{2}\right)$ is a Gaussian activation function. $c_{x j}$ and $v_{x j}$ are, respectively, the center and the 
width of the $j$ th node. Proj is the projection function on the compact $\Gamma_{\omega_{x}}=\left\{\omega_{x}:\left\|\omega_{x}\right\| \leq \mathfrak{R}_{\omega_{x}}\right\}$. The weight vectors $\widehat{\omega}_{x y}$ are initialized in a uniformly random manner while the centers and the widths are selected according to the clustering method as [42]

$$
\begin{aligned}
& c_{x \jmath}=\chi_{x \min }+\frac{2 \jmath-1}{2} v_{x \jmath} \\
& v_{x \jmath}=\frac{\chi_{x \max }-\chi_{x \min }}{N},
\end{aligned}
$$

where $\chi_{x \min }$ and $\chi_{x \max }$ state, respectively, the lower and the upper bounds of the input vector $\chi_{x}^{T}$.

The proof of the convergence of the above NNs controllers is found in [30].

Remark 3. During the startup phase, given that the weights vector is randomly initialized, the network may take a relatively long time to converge. This implies that the network uncertainties are more significant during this phase. Unfortunately the estimations of the network uncertainties bounds given in (43), (44), and (45) start from 0 before increasing to sufficient values. An obvious solution is to take a too high estimation rate $\alpha_{x}, x=i_{s d}, \Omega, u$. But a too large rate $\alpha_{x}$ may excite high frequency unmodeled dynamics, maintain higher control effort, and render the system unstable.

To address this issue, a transformation for the estimation of uncertainties bound is proposed. This transformation seeks to steer the tracking error to the origin and also allow the tracking process to be explicitly controllable so that the rate of convergence during the startup phase can be smoothly pre-specified and faster. In concrete terms, define

$$
\hat{\lambda}_{x}^{*}=\hat{\lambda}_{x} \kappa_{x}(t), \quad x=i_{s d}, \Omega, u
$$

where $\hat{\lambda}_{x}^{*}$ is the transformed $\hat{\lambda}_{x}$ and $\kappa_{x}(t)$, a smooth decreasing function that satisfies

$$
\begin{aligned}
\kappa_{x}(t) & >0, \\
\lim _{t \longrightarrow \infty} \kappa_{x}(t) & =1, \\
\kappa_{x}(0) & =\kappa_{\text {xmax }},
\end{aligned}
$$

$\kappa_{x \max }$ is the maximum value of $\kappa_{x}(t)$. For example, the function

$$
\kappa_{x}(t)=1+\gamma_{x} e^{-\sigma_{x} t}, \quad \gamma_{x}, \sigma_{x}>0
$$

is a good candidate and may be used in (49).

Considering the aforementioned transformation, the bias terms in (40), (41), and (42) become

$$
\begin{aligned}
b_{i_{s d}}^{*}(t) & =\widehat{\lambda}_{i_{s d}} \kappa_{i_{s d}}(t) \operatorname{sign}\left(S_{i_{s d}}\right) \\
b_{\Omega}^{*}(t) & =-\hat{\lambda}_{\Omega} \kappa_{\Omega}(t) \operatorname{sign}\left(S_{\Omega}\right)
\end{aligned}
$$

$$
\begin{aligned}
& b_{u}^{*}(t)=\hat{\lambda}_{u} \kappa_{u}(t) \operatorname{sign}\left(S_{u}\right) \\
& \kappa_{i_{s d}}(t)=1+\gamma_{i_{s d}} e^{-\sigma_{i_{s d}} t}, \\
& \kappa_{\Omega}(t)=1+\gamma_{\Omega} e^{-\sigma_{\Omega} t}, \\
& \kappa_{u}(t)=1+\gamma_{u} e^{-\sigma_{u} t}
\end{aligned}
$$

where $\gamma_{x}>0$ and $\sigma_{x}>0, x=i_{s d}, \Omega$, are specified by the designer.

It is well known that online identification and adaptation of a time varying parameter in a controller contribute to relax the requirement of the system parameter knowledge and help to improve the control performance [43]. Such is the purpose of the following rotor flux identifier. Substitute $T_{m}$ by $K_{o p t} \Omega^{2}$ in (5) and rearrange it as

$$
\dot{\Omega}=\frac{K_{o p t} \Omega^{2}-f \Omega}{J}-\frac{3 p}{2 J} \phi_{r} i_{s q}
$$

Based on (57), a generator speed observer can be written as $\left(K_{1}>0\right.$ is a constant gain)

$$
\begin{aligned}
\dot{\widehat{\Omega}} & =\frac{K_{o p t} \Omega^{2}-f \Omega}{J}-\frac{3 p}{2 J} \widehat{\phi}_{r} i_{s q}-v, \\
v & =K_{1} \operatorname{sign}(\widetilde{\Omega}) .
\end{aligned}
$$

Computing the dynamic of observation error yields

$$
\dot{\widetilde{\Omega}}=-\frac{3 p}{2 J} \widetilde{\phi}_{r} i_{s q}-v
$$

where $\widehat{\Omega}$ and $\widehat{\phi}_{r}$ denote the estimated quantities while $\widetilde{\Omega}=$ $\widehat{\Omega}-\Omega$ and $\widetilde{\phi}_{r}=\widehat{\phi}_{r}-\phi_{r}$ are the error quantities. Assuming that the parameter identifiability condition $-3 p i_{s q} / 2 J \neq 0 \forall t \geq 0$ is verified, the rotor flux estimation law can be processed as $\left(K_{2}, \tau>0\right.$ and $s$ is Laplace variable)

$$
\begin{aligned}
\dot{\widehat{\Omega}} & =\frac{K_{o p t} \Omega^{2}-f \Omega}{J}-\frac{3 p}{2 J} \widehat{\phi}_{r} i_{s q}-v \\
\dot{\bar{\phi}}_{r} & =\dot{\widehat{\phi}}_{r}=-K_{2} \widetilde{\phi}_{r}, \\
\tilde{\phi}_{r} & =\frac{v_{1 e q}}{-(3 p / 2 J) i_{s q}} \\
v & =K_{1} \operatorname{sign}(\widetilde{\Omega}), \\
v_{e q} & =\frac{v}{1+\tau s} .
\end{aligned}
$$

The proof of convergence of the identification algorithm in ((61)-(63)) can be found in [24].

The schematic description of the proposed control algorithm is presented in Figure 2. In this figure, graphs (a), (b), and (c) show the equivalent control systems while graph (d) exhibits the interface of the control inputs with PWM units. $\theta$ is the generator shaft position. 


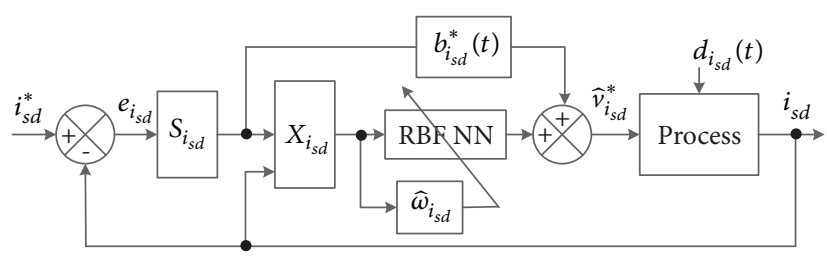

(a)

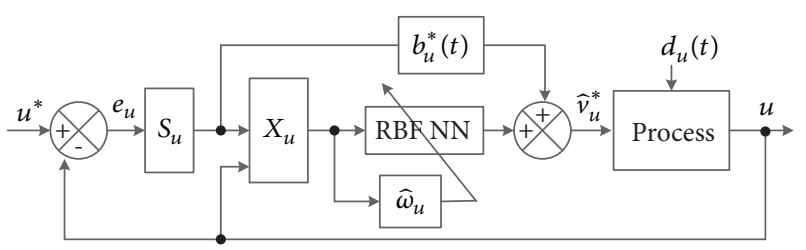

(c)

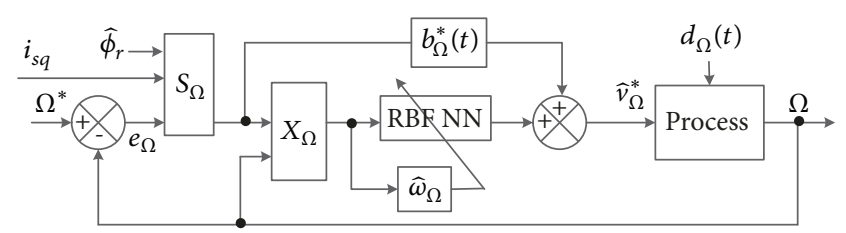

(b)

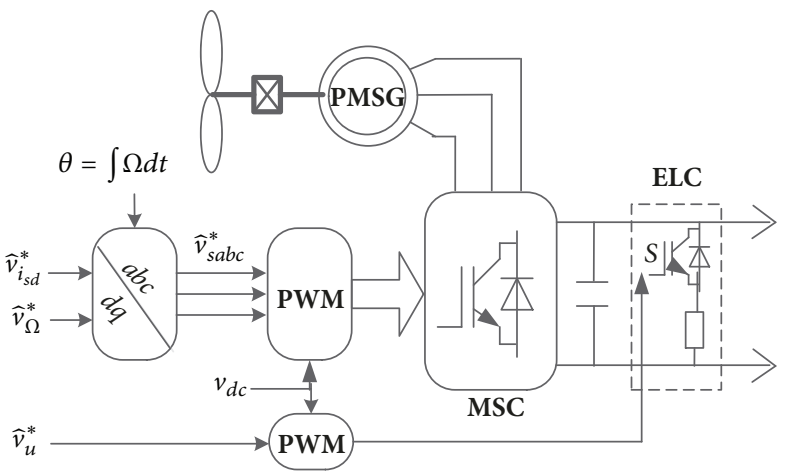

(d)

FIGURE 2: Block diagram of the proposed RBF neuro-sliding controller.

\section{Control Design for GSC}

The GSC, acting as a voltage source inverter, is controlled to track the active and reactive power of the grid by using grid current regulator. Conventional PI control method is exploited in the present study to achieve the control objective. Details concerning the selection of PI gains are described in Appendix. Figure 3 illustrates the proposed GSC control structure. $\theta_{g}$ is the grid voltage angular position estimated by a PLL for grid synchronization.

The references of the grid current components are computed from the reference active power $P^{*}$ and reference reactive power $Q^{*}$ as follows:

$$
\begin{aligned}
& i_{G d}^{*}=\frac{2}{3} \frac{P^{*} v_{g d}+Q^{*} v_{g q}}{v_{g d}^{2}+v_{g q}^{2}}, \\
& i_{G q}^{*}=\frac{2}{3} \frac{P^{*} v_{g q}-Q^{*} v_{g q}}{v_{g d}^{2}+v_{g q}^{2}} .
\end{aligned}
$$

In order to allow the GSC to operate at unity power factor, $Q^{*}$ is set to zero. The reference active power is derived directly from the optimum power captured from the WT as shown in (65).

$$
P^{*}=K_{o p t} \Omega_{o p t}^{3}-\frac{S u}{C R_{E}}
$$

Remark 4. In standalone mode, the GSC is controlled to regulate the amplitude and frequency of the AC load voltage. From the grid current control structure in Figure 3, it is possible to switch to standalone mode by disconnecting the grid and setting manually the reference components $\left(v_{d}^{*}\right.$ and $v_{q}^{*}$ ) of the voltage across the filter capacitor and the value of the load voltage angular frequency for $(d, q)-(a, b, c)$ reference frame transformation. The switches in Figure 3 together with the circuit breaker are dedicated to this end. That is an interesting feature of the proposed inverter control structure.

\section{Numerical Simulation Results}

Numerical simulations of the studied WECS (see Figure 1 with control structures in Figures 2 and 3) are carried out in Matlab/Simulink software to assess the performance of the proposed RBF neuro-sliding mode controller (RBF-NSMC). Simulations based on a sliding mode control (SMC) method [24] are conducted and the results are presented to compare the capabilities of the proposed RBF-NSMC. The WECS parameters [44] and the numerical values of the control parameters are listed in Tables 1 and 2, respectively. It is worth mentioning that the PMSG can directly be connected to the WT. However, a gearbox ratio $G=1.2$ is selected to comply with realistic transmission condition. An inductive RL load $(R=250 \Omega$ and $L=50 \mathrm{mH})$ is used to materialize a general local ACload. More details on the selection criteria of the LCL filter parameters are given in Appendix. Each neural network is built up with four neurons in the hidden layer.

The analysis of the system response is conducted considering three operation conditions. Firstly the effectiveness of the proposed RBF-NSMC is investigated under nominal WECS parameters (see Figures 4-9). Secondly the robustness of the controller is examined under WECS parameters uncertainties (see Figures 10-12). The wind speed is time varying in both cases and its behaviour is shown in Figure 4. Finally the performance of the control system is evaluated under transition from grid connected to standalone mode during low wind speeds (see Figures 13 and 14). 


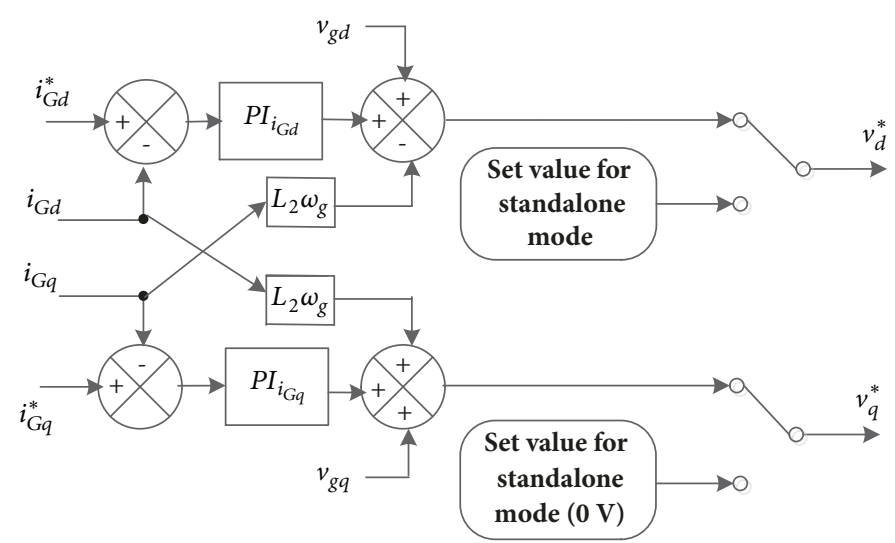

(a)

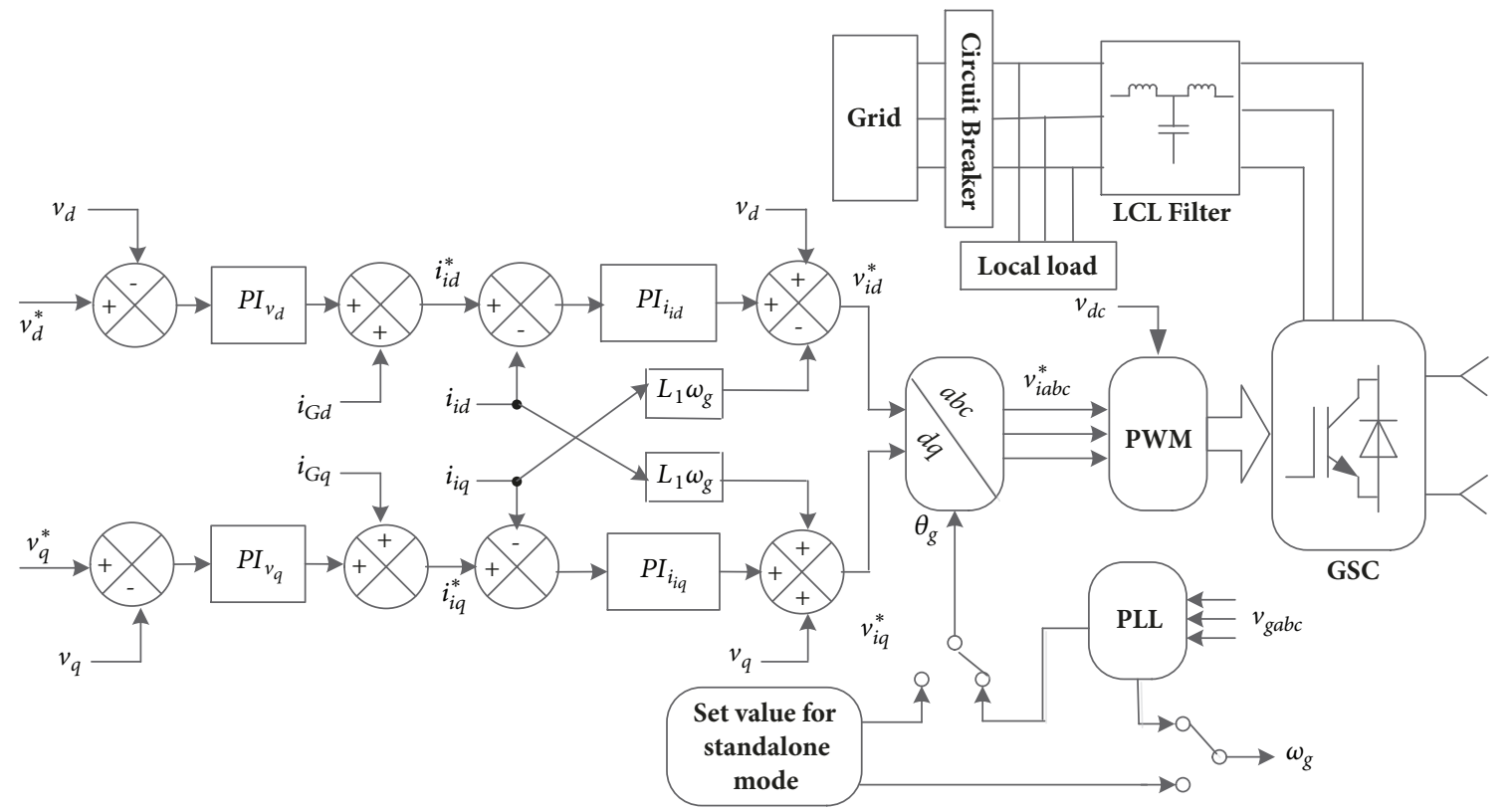

(b)

FIGURE 3: GSC control diagram. (a) Grid current control loop. (b) Control loop for LCL filter capacitor voltage.

(i)

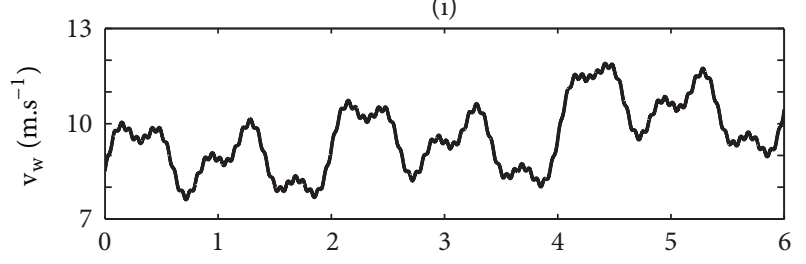

(ii)

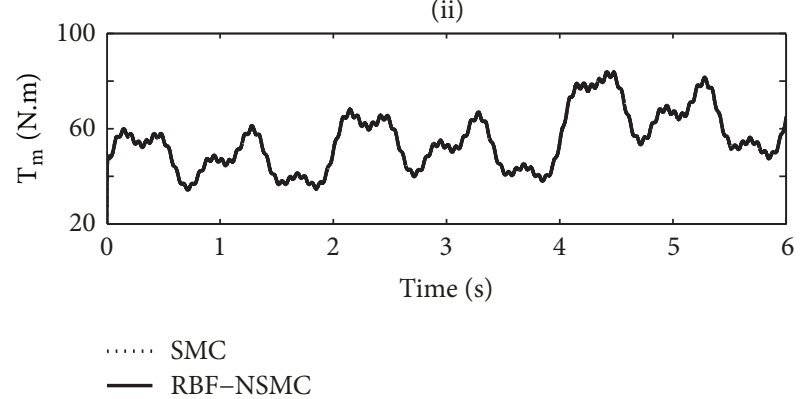

FIGURE 4: Wind speed profile and consequent mechanical torque.
Case 1 (test under varying wind speed with WECS nominal parameters). It can be observed on Figures 4-7 that the control objective of the generator side converter and dc-link is achieved since the generator $d$-axis current is rapidly set to zero (see Figure 5), the dc voltage is regulated to the desired reference value, and the maximum power is accurately harnessed from the wind (see Figure 6). For this test, one can remark clearly on Figure 7 that the results provided by both proposed RBF-NSMC and SMC methods are practically similar. Figures 8 and 9 exhibit the behaviour of the grid side signals when the proposed control approach is maintained on the machine side and dc-link. It is noticeable from Figure 8(a) that the grid $d q$ current components are steered to their estimated references with small response time. Figure 8(b) shows that the regulation of the voltage across the LCL filter capacitor is satisfactory. This voltage regulation is necessary for local AC load feeding and grid synchronization. The sinusoidal waveforms of the filter capacitor voltage and the total grid plus local load current are depicted in Figure 9. From 
(i)

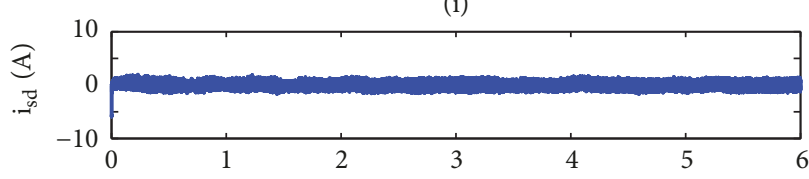

- RBF-NSMC

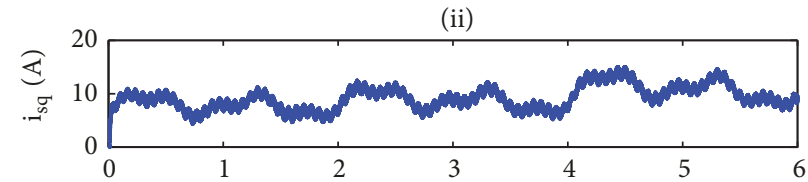

- RBF-NSMC

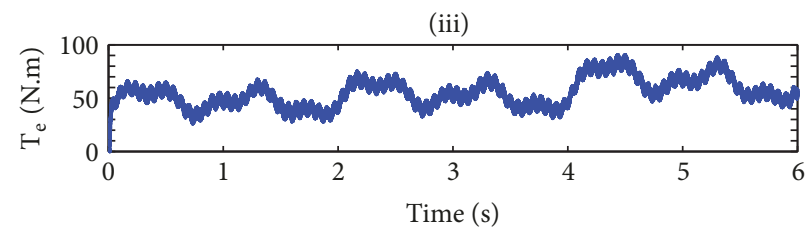

- RBF-NSMC

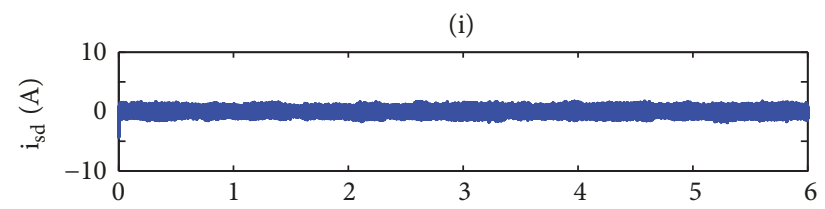

- SMC

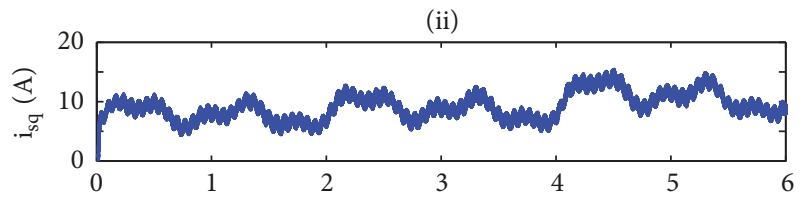

(iii)

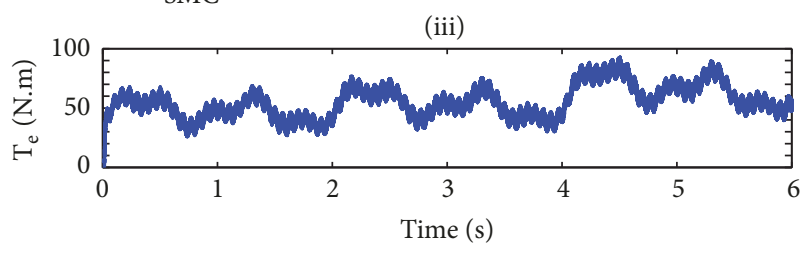

- SMC

(a)

(b)

FIGURE 5: Control system response to wind speed fluctuations with nominal values of parameters. (a) Proposed controller. (b) Sliding mode controller. (i) Generator $d$-axis current. (ii) Generator $q$-axis current. (iii) Electromagnetic torque.
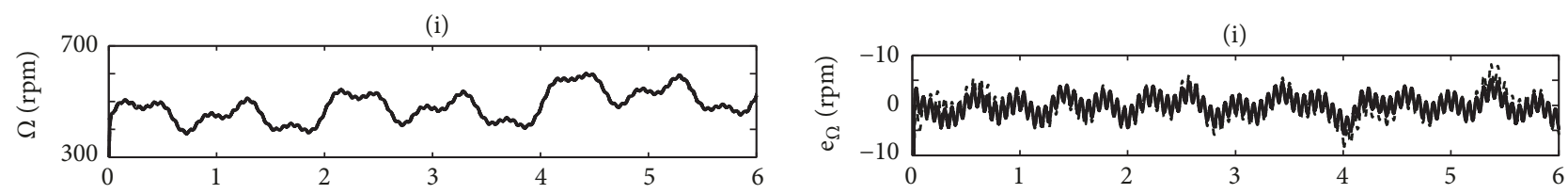

$\begin{array}{ll}\ldots . . . & \text { Reference } \\ \text { - - - SMC }\end{array}$

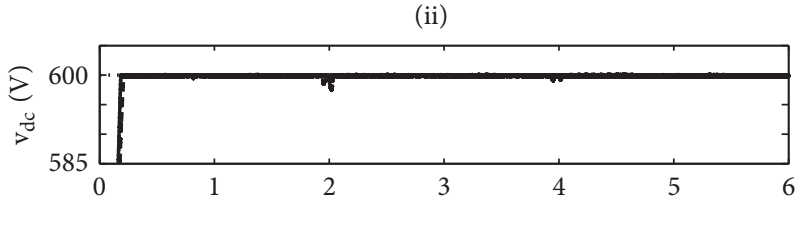

...... Reference

- - SMC

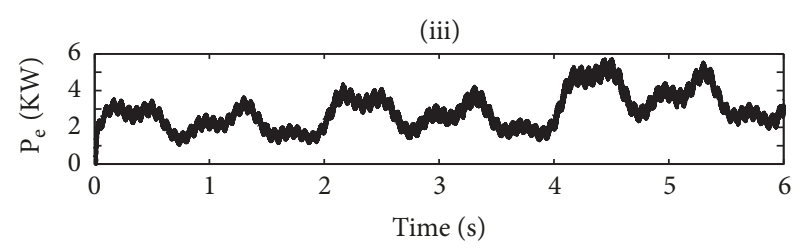

..... Reference

- - - SMC
- RBF-NSMC

(a)

\section{--- SMC \\ - RBF-NSMC}

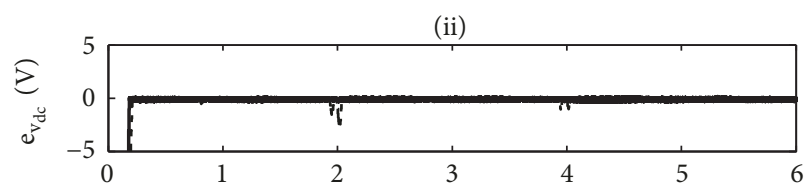

--- SMC

- RBF-NSMC

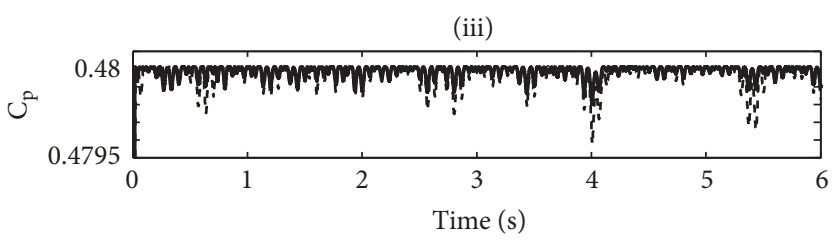

- - $\mathrm{SMC}$

- RBF-NSMC

FIGURE 6: Control system response to wind speed fluctuations with nominal values of parameters. (a) (i) Generator speed, (ii) dc-link voltage, and (iii) generator electrical power. (b) (i) Generator speed error, (ii) dc-link voltage error, and (iii) power coefficient. 
(i)

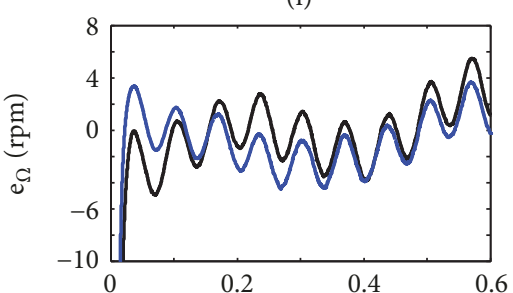

(ii)

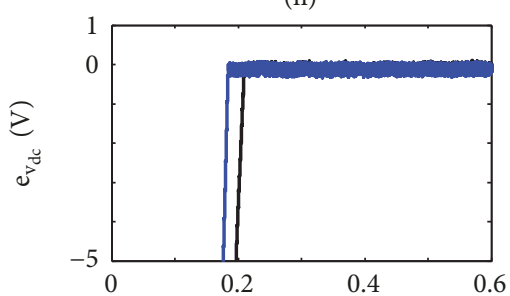

(iii)

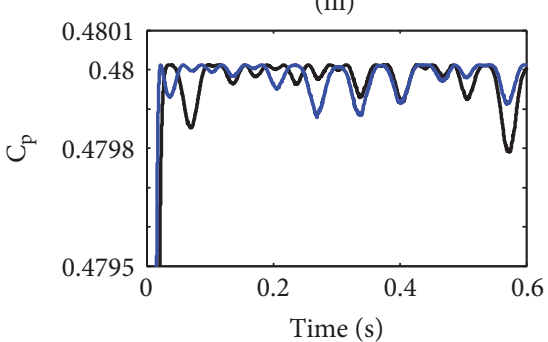

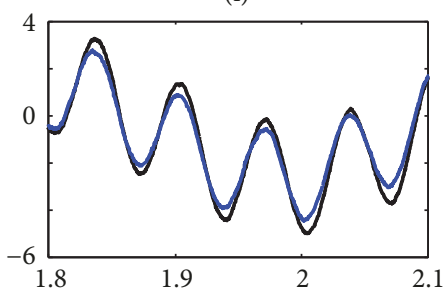

(ii)

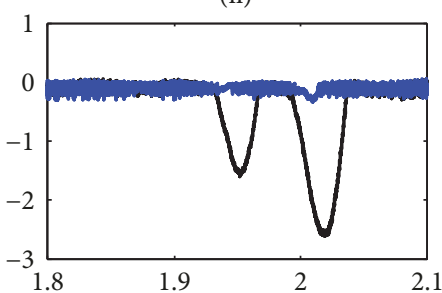

(iii)

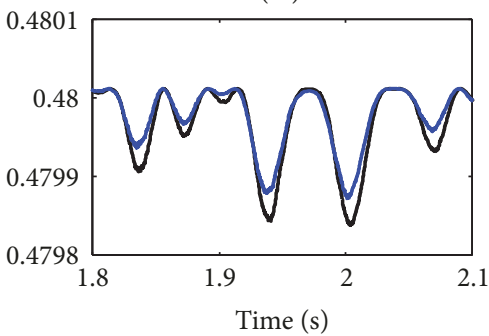

(i)

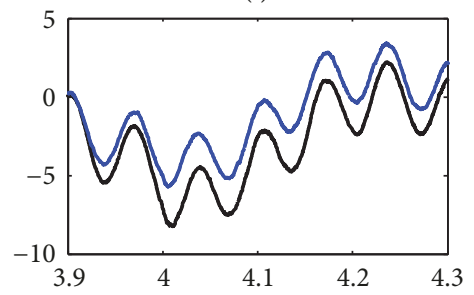

(ii)

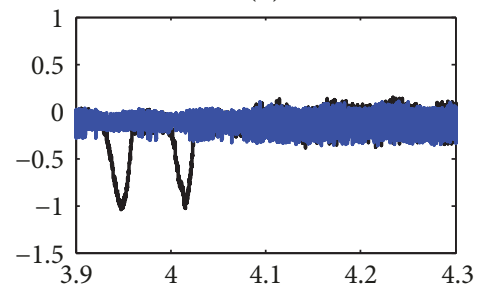

(iii)

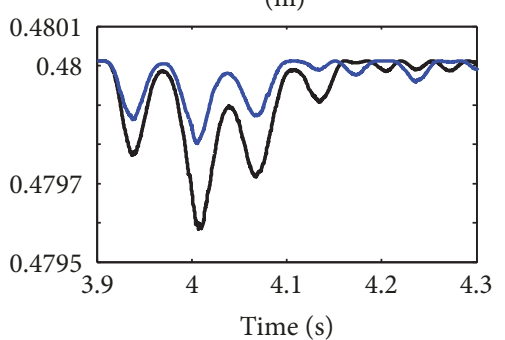

(a)

FIGURE 7: Control system response to wind speed fluctuations with nominal values of parameters. Zoom on (blue line: RBF-NSMC, black line: SMC): (i) Generator speed error, (ii) dc-link voltage error, and (iii) power coefficient.

(i)

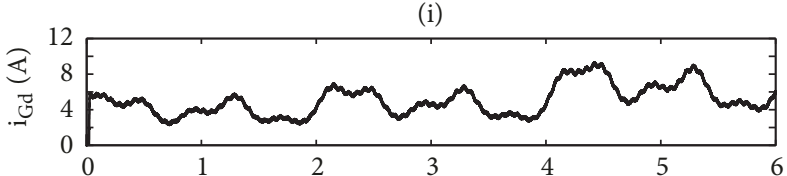

— RBF-NSMC

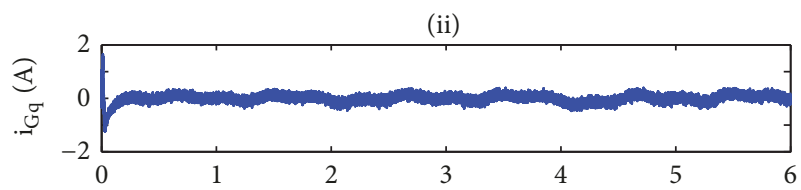

- RBF-NSMC

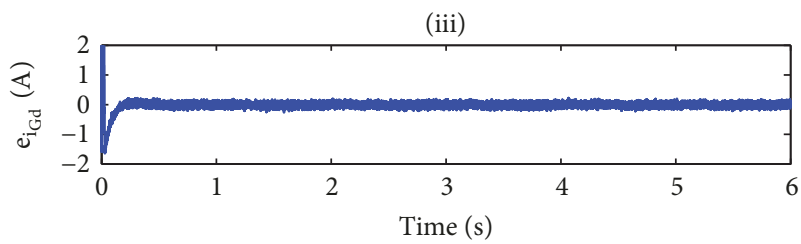

- RBF-NSMC

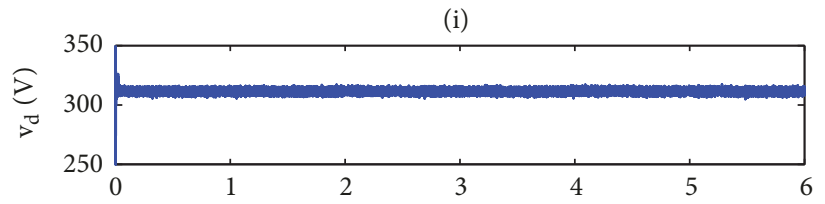

- RBF-NSMC

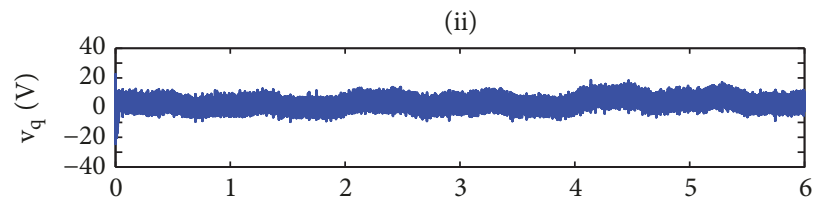

- RBF-NSMC

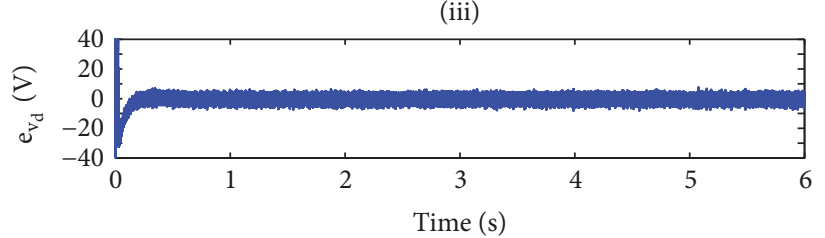

- RBF-NSMC

(b)

FIGURE 8: Control system response to wind speed fluctuations with nominal values of parameters. (a) (i) Grid $d$-axis current, (ii) grid q-axis current, and (iii) grid $d$-axis current error. (b) (i) $d$-axis voltage across LCL filter capacitor, (ii) $d$-axis voltage across LCL filter capacitor, and (iii) error signal of $d$-axis voltage across LCL filter capacitor. 
TABLE 1: Nominal values of PMSG WECS parameters.

\begin{tabular}{|c|c|c|c|c|}
\hline \multirow{2}{*}{ Wind turbine } & $\beta=0$ & $\zeta_{o p t}=8.1$ & $C_{\text {pmax }}=0.48$ & $\rho=1.225 \mathrm{Kg} \cdot \mathrm{m}^{-} 3$ \\
\hline & $G=1.2$ & $r=1.84 m$ & $J=7.856 \mathrm{Kg} \cdot \mathrm{m}^{2}$ & \\
\hline PMSG & $R_{s}=0.3676 \Omega$ & $L_{s}=3.55 \mathrm{mH}$ & $\phi_{r}=0.2867 W b$ & $2 p=28$ \\
\hline dc-link & $C=2200 \mu F$ & $v_{d c}=600 \mathrm{~V}$ & & \\
\hline
\end{tabular}

TABLE 2: Numerical values of control parameters.

\begin{tabular}{lccccc}
\hline MSC control & \multicolumn{7}{c}{} \\
\hline$d$-axis current controller & $h_{1}=10$ & $\alpha_{i_{s d}}=20000$ & $\gamma_{i_{s d}}=10$ & $\sigma_{i_{s d}}=5$ & $\epsilon_{i_{s d}}=0.1$ \\
Rotor speed regulator & $h_{2}=190$ & $h_{3}=1200$ & $\alpha_{\Omega}=20000$ & $\gamma_{\Omega}=15$ & $\sigma_{\Omega}=5$ \\
dc voltage control & $\alpha_{u}=5000$ & $\gamma_{u}=0$ & $\sigma_{u}=0$ & $\epsilon_{u}=0.1$ & \\
Rotor flux estimation & $K_{1}=10$ & $K_{2}=8000$ & & & \\
\hline GSC Control & $K_{P i_{G d}}=18$ & $K_{I i_{G d}}=45.5$ & $K_{P i_{G q}}=18$ & $K_{I i_{G q}}=45.5$ \\
\hline Grid current regulation & $K_{P v_{d}}=0.07$ & $K_{I v_{d}}=1$ & $K_{P v_{q}}=0.07$ & $K_{I v_{q}}=1$ \\
LCL capacitor voltage control & $K_{P i_{i d}}=75$ & $K_{I i_{i d}}=482$ & $K_{P i_{i q}}=75$ & $K_{I i_{i q}}=482$ \\
GSC current control & & &
\end{tabular}

the above observations one can undoubtedly conclude that the proposed control scheme is effective and the extracted optimum power is transferred to the load with unity power factor.

Case 2 (test under varying wind speed with WECS parameters uncertainties). The graphs on Figures 10-12 show the results obtained when uncertainties are introduced on the process parameters at time $t=1 \mathrm{~s}$. These perturbations consist of $+100 \%,+50 \%,-20 \%$, and $+30 \%$ sudden changes on the nominal values of stator resistance, stator inductance, rotor flux, and rotor inertia, respectively. From Figure 10, one can note that the proposed controller presents fast dynamic response compared to that of the SMC one. The absolute values of tracking errors representing maximum deviations from the optimal curve, for different time periods, are picked up from Figure 10(b) and presented in Table 3. It comes out from this table that the deviations under the proposed RBFNSMC method are always smaller than those provided by the SMC. This demonstrates that the proposed control scheme features higher robustness with respect to varying wind speed and parameter disturbances. It is shown in Figure 11(a) that the transformed estimation of the unknown uncertainties bound starts with a high value to accelerate the process and converges to a low value to reduce the energy consumed by the controller and also prevent from unwanted high frequency unmodeled dynamics. The resulting smooth control actions for both MSC and GSC are shown in Figure 11(b). These control actions are very significant since they are not saturated and therefore are favorable for interfacing with PWM units. This remark supports the fact that the proposed RBF-NSMC is feasible for real time implementation. The total harmonic distortions (THDs) of the LCL filter capacitor voltage and injected grid current are both less than 5\% which is the upper limit as seen in Figure 12. Although this study is focused on the grid connected mode, one may say that, for wind speeds lower than those depicted in the used wind profile, one can switch to standalone mode as stated in
Remark 4. This helps not to exceed the 5\% THD maximum value on the injected grid current.

Case 3 (performance evaluation under grid connected to standalone mode transition). In this test, the system starts with the same conditions as in Case 2. But at time $t=1.84 \mathrm{~s}$, the mean value of the wind profile changes to low value (from $8.5 \mathrm{~m} \cdot \mathrm{s}^{-1}$ to $5.5 \mathrm{~m} \cdot \mathrm{s}^{-1}$, see Figure 13). Simultaneously the system is switched to standalone mode (see Remark 4). It is observed on Figure 14(a) that the global stability of the system is preserved and better transient performance is kept by the proposed RBF-NSMC as compared to the SMC. It is seen on Figure 14(b) that the filter capacitor voltage is still well regulated by the proposed grid side PI controller despite the grid disconnection. It is also noted that, after this grid disconnection, the injected grid current vanishes and only the portion absorbed by the local load remains. These observations demonstrate the flexible feature of the proposed grid side control structure.

\section{Conclusions}

A control scheme of a grid connected variable speed PMSG WECS is investigated. The control approach based on online learning RBF-sliding network has been proposed to extract efficiently maximum power without the knowledge of neither the exact model of the nonlinear system nor the requirement of the upper limit of the system disturbances. A transformation of the estimated system uncertainties bound for explicitly accelerating the rate of convergence of the NN during startup phase has been proposed. Simulation results have shown the effectiveness and the feasibility of the proposed control scheme. The proposed RBF-NSMC exhibited higher robustness with fast dynamic response face to wind speed variations and WECS parameters changes. The proposed grid side inverter control structure is flexible so as to switch between grid connected mode and standalone mode in order to cover both high and low wind speeds. 
(i)

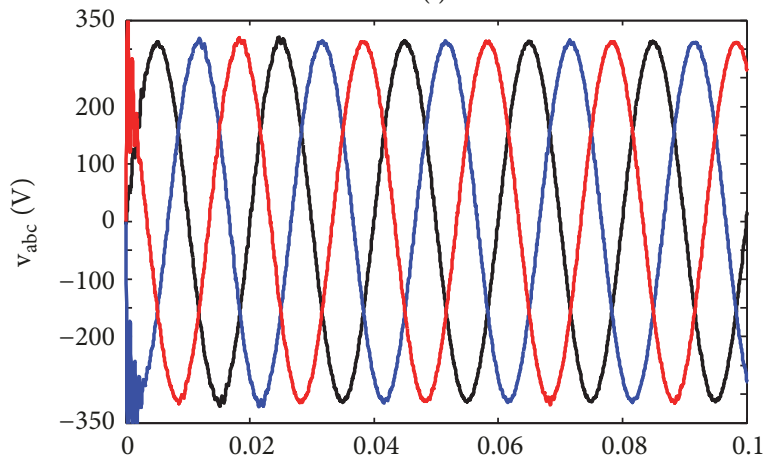

(ii)

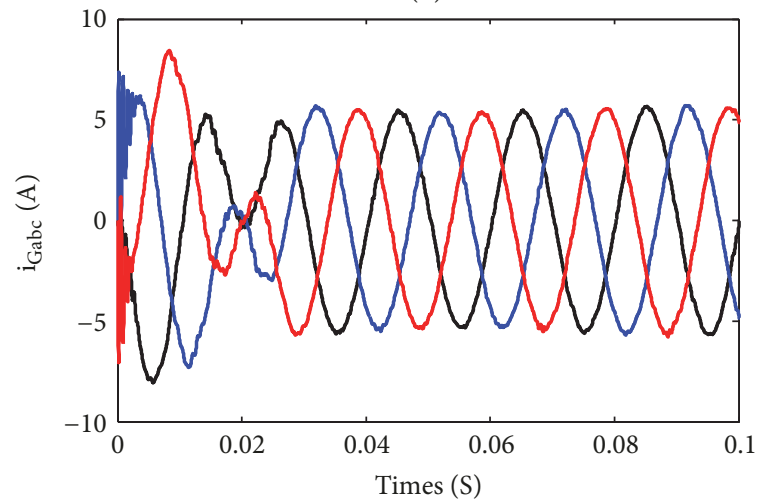

(i)

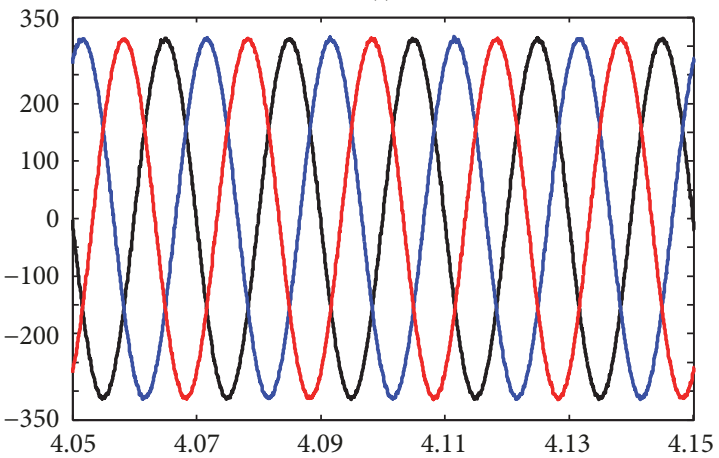

(ii)

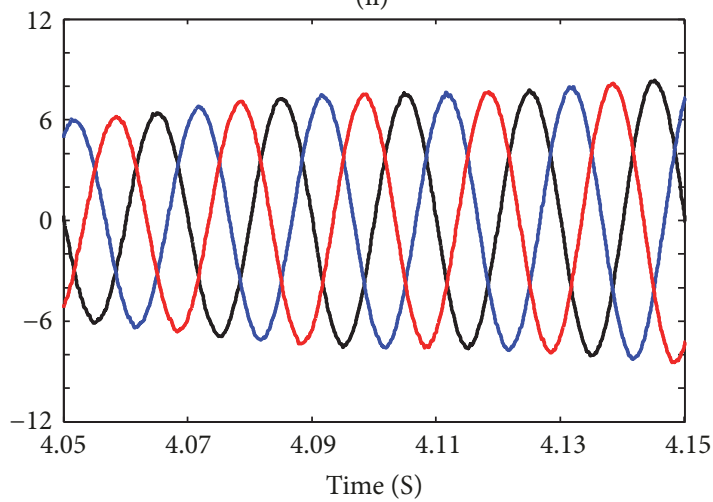

FIGURE 9: Control system response to wind speed fluctuations with nominal values of parameters. Zoom on (proposed RBF-NSMC): (i) 3-phase voltage across the LCL filter capacitor and (ii) 3-phase total grid plus local load current.

TABLE 3: Comparison of maximum deviations from the optimal curve under varying wind speed with parametric perturbations.

\begin{tabular}{|c|c|c|c|c|c|c|}
\hline Time period (s) & \multicolumn{2}{|c|}{$t \in\left[\begin{array}{ll}0.9 & 1.3\end{array}\right]$} & \multicolumn{2}{|c|}{$t \in\left[\begin{array}{ll}1.8 & 2.2\end{array}\right]$} & \multicolumn{2}{|c|}{$t \in\left[\begin{array}{ll}3.9 & 4.2\end{array}\right]$} \\
\hline Controller & RBF-NSMC & SMC & RBF-NSMC & SMC & RBF-NSMC & SMC \\
\hline$\left|e_{\Omega}\right|_{\max }(r p m)$ & 8.5336 & 9.7521 & 6.0294 & 9.8529 & 6.3361 & 8.4202 \\
\hline$\left|e_{v_{d c}}\right|_{\max }(V)$ & 0.8992 & 1.6050 & 3.5966 & 7.8319 & 3.9286 & 12.5000 \\
\hline$\left|C_{p}-C_{p \max }\right|_{\max }(-)$ & 0.0005 & 0.0007 & 0.0003 & 0.0007 & 0.0002 & 0.0004 \\
\hline
\end{tabular}

\section{Appendix}

\section{A. Selection of GSC PI Control Gains}

In this reasoning $K_{P x}$ and $K_{I x}$ represent proportional and integral gains, respectively, and $e_{x}=x^{*}-x$ quotes the error signal, while $x$ is a signal with $x^{*}$ being the corresponding reference. Rearrange (19) and (20) in the following form:

$$
\begin{aligned}
L_{2} \dot{i}_{G d} & =-R_{2} i_{G d}+v_{d}^{\prime}, \\
v_{d}^{\prime} & =L_{2} \omega_{g} i_{G q}-v_{g d} \\
L_{2} \dot{i}_{G q} & =-R_{2} i_{G q}+v_{q}^{\prime}, \\
v_{q}^{\prime} & =-L_{2} \omega_{g} i_{G d}-v_{g q}
\end{aligned}
$$

$v_{d}^{\prime}$ and $v_{q}^{\prime}$ are the transformed control inputs. And compute the open loop transfer functions of (A.1) and (A.3)

$$
H_{i_{G d}}^{o l}(s)=H_{i_{G q}}^{o l}(s)=\frac{1 / R_{2}}{\tau_{i_{G}}^{o l} s+1}
$$

where $\tau_{i_{G}}^{o l}=L_{2} / R_{2}$ is the open loop time constant. Now select the correctors in the form of

$$
\begin{aligned}
C_{i_{G d}}(s) & =C_{i_{G q}}(s)=K_{P i_{G}}+\frac{K_{I i_{G}}}{s}=\frac{K_{P i_{G}}\left(a_{i_{G}} s+1\right)}{a_{i_{G}} s}, \\
a_{i_{G}} & =\frac{K_{P i_{G}}}{K_{I i_{G}}}
\end{aligned}
$$

Proceed to the compensation of the open loop time constant by choosing $a_{i_{G}}$ as

$$
a_{i_{G}}=\tau_{i_{G}}^{o l}
$$

and calculate the corrected closed loop transfer functions in the form of first-order systems as

$$
H_{i_{G d}}^{c l}(s)=H_{i_{G q}}^{c l}(s)=\frac{1}{\tau_{i_{G}}^{c l} s+1}
$$




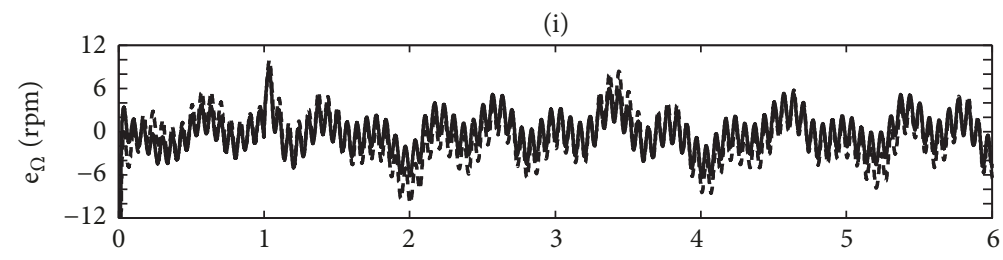

-.- SMC

- RBF-NSMC

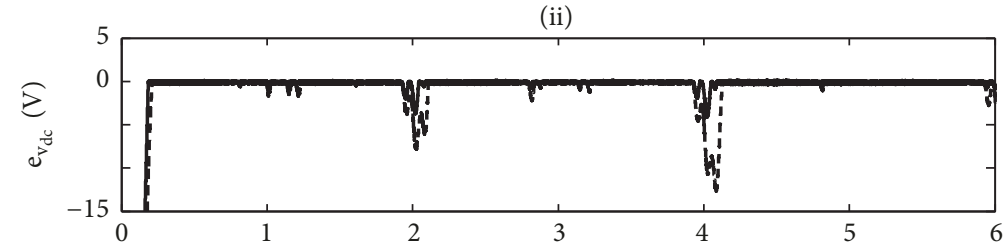

- - - SMC

- RBF-NSMC

(iii)

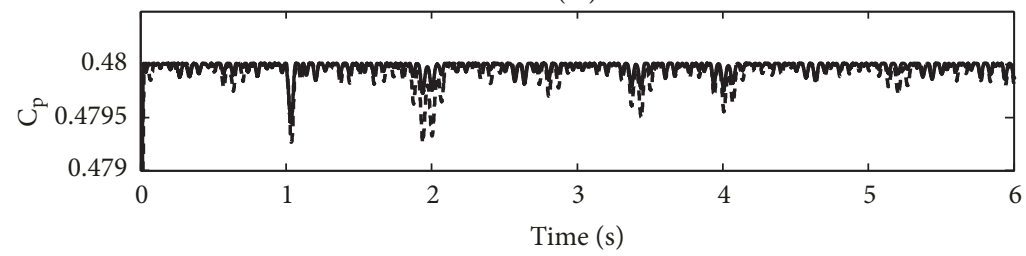

- - SMC

RBF-NSMC

(a)

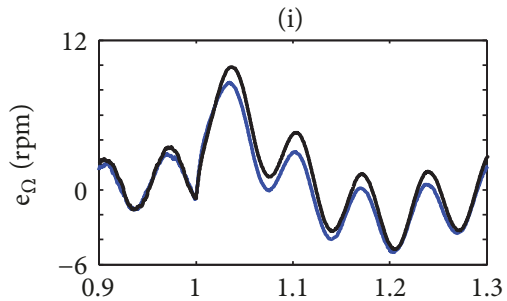

(ii)

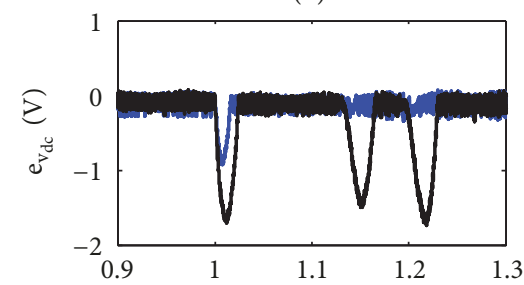

(iii)

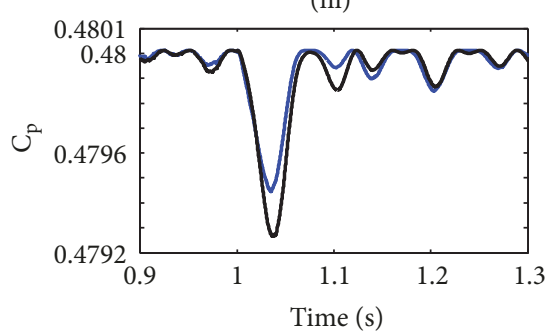

(i)

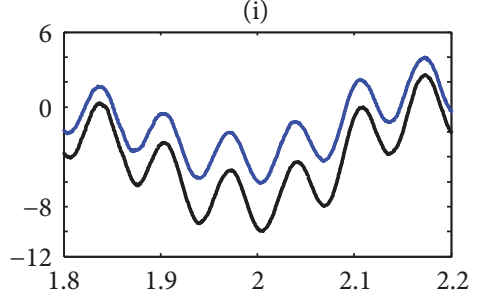

(ii)

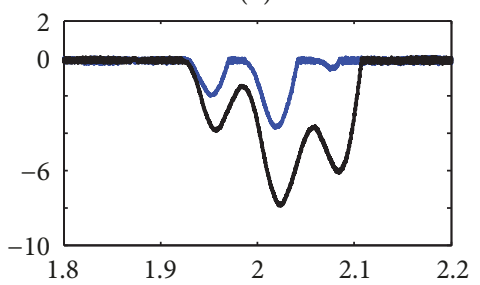

(iii)

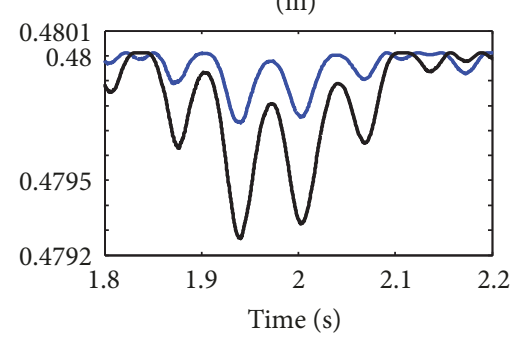

(i)

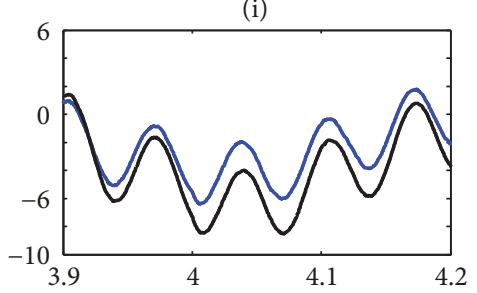

(ii)

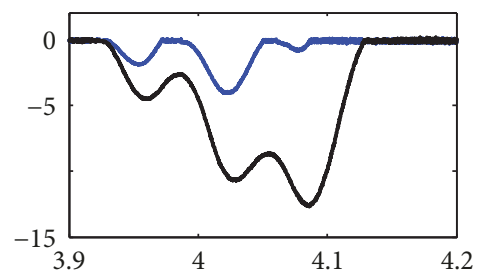

(iii)

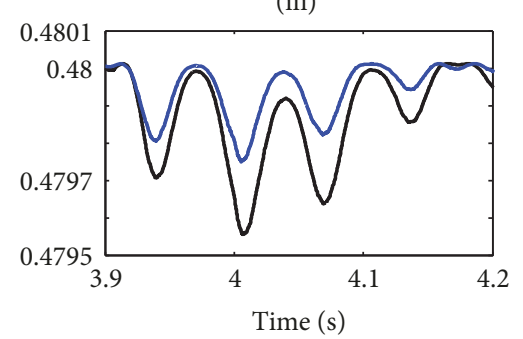

(b)

FIGURE 10: Control system response to wind speed fluctuations with parameters uncertainties (at time $t=1 \mathrm{~s}$, variations of $+100 \%$ for $R_{s}$, $+50 \%$ for $L_{s},-20 \%$ for $\phi_{r}$, and $+30 \%$ for $J$ are introduced). (a) Signals trajectories and (b) corresponding zoom (blue line: RBF-NSMC, black line: SMC). (i) Generator speed error, (ii) dc-link voltage error, and (iii) power coefficient. 

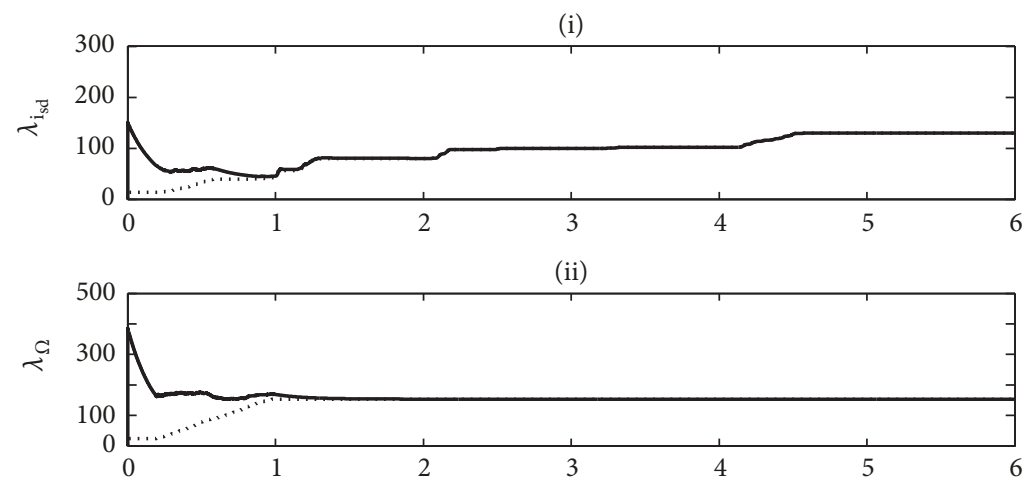

(iii)

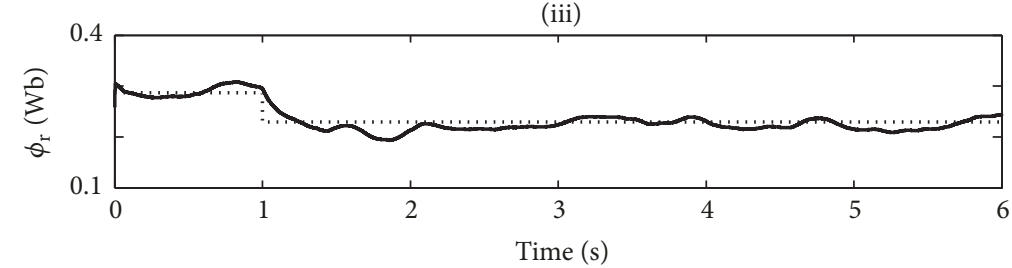

(a)

(i)

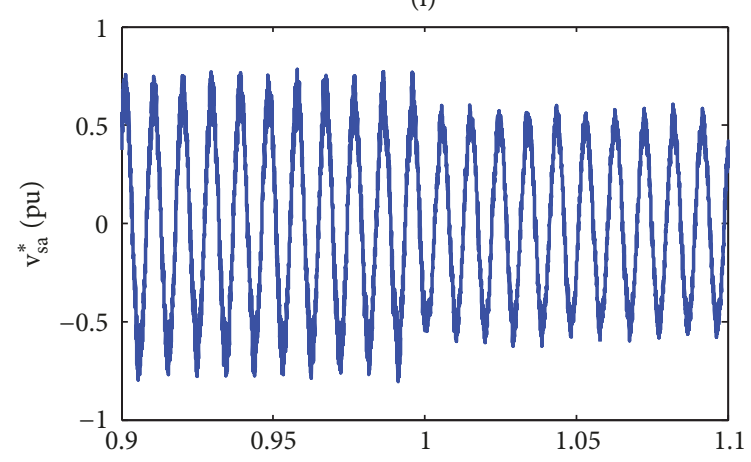

RBF-NSMC

(ii)

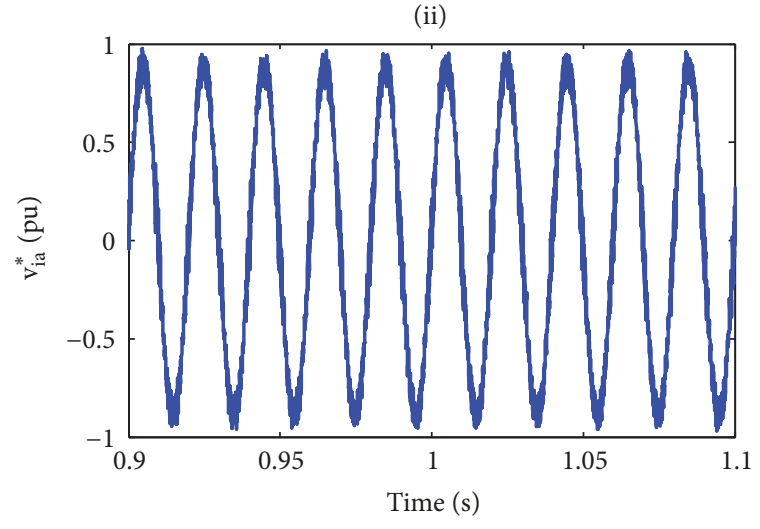

- RBF-NSMC (i)

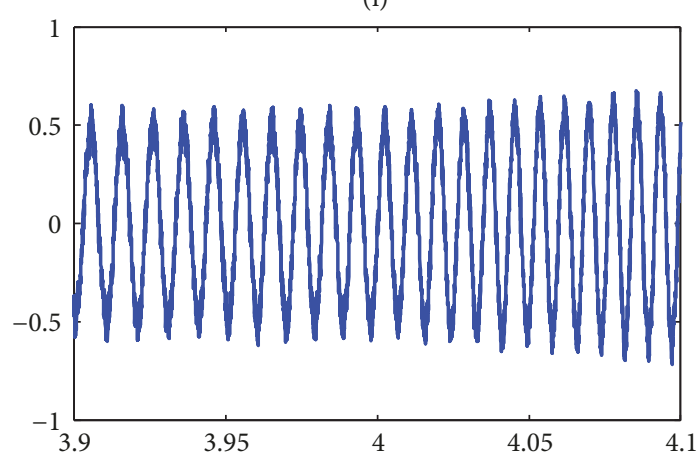

RBF-NSMC

(ii)

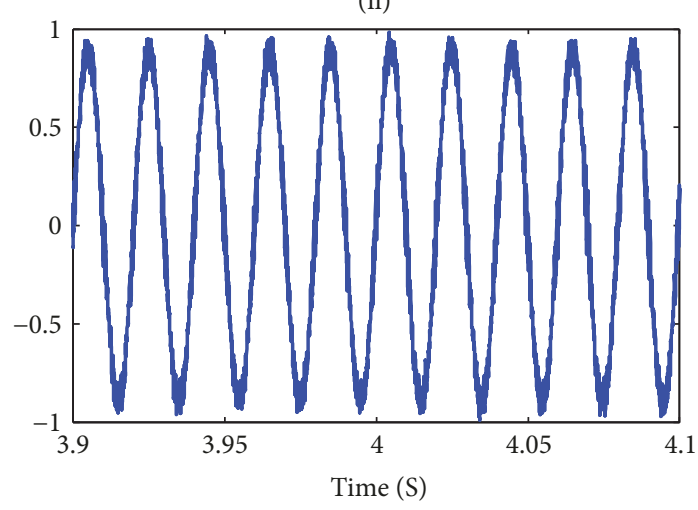

- RBF-NSMC

(b)

FigURE 11: Control system response to wind speed fluctuations with parameters uncertainties (at time $t=1 \mathrm{~s}$, variations of $+100 \%$ for $R_{s}$, $+50 \%$ for $L_{s},-20 \%$ for $\phi_{r}$, and $+30 \%$ for $J$ are introduced). (a) Estimated parameters. (i) $\lambda_{i_{s d}}$ (dotted line) estimate $\left(\widehat{\lambda}_{i_{s d}}\right.$ ) and (solid line) its transformed estimate $\left(\widehat{\lambda}_{i_{s d}}^{*}\right)$, (ii) $\lambda_{\Omega}$ : (dotted line) estimate $\left(\widehat{\lambda}_{\Omega}\right)$ and (solid line) its transformed estimate $\left(\widehat{\lambda}_{\Omega}^{*}\right)$, and (iii) $\phi_{r}$ : (dotted line) reference and (solid line) its estimate. (b) Zoom on control signals: (i) approximation of phase- $a$ voltage of the MSC $\widehat{v}_{s a}^{*}$; (ii) phase- $a$ voltage of the GSC $v_{i a}^{*}$. 


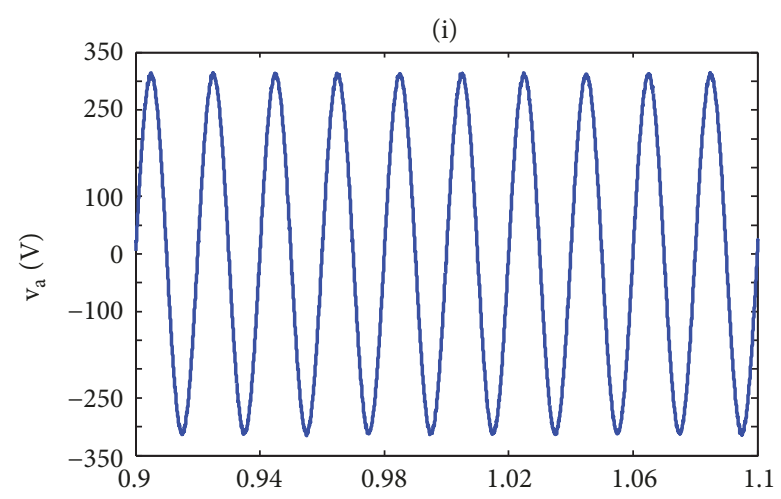

- RBF-NSMC

(ii)

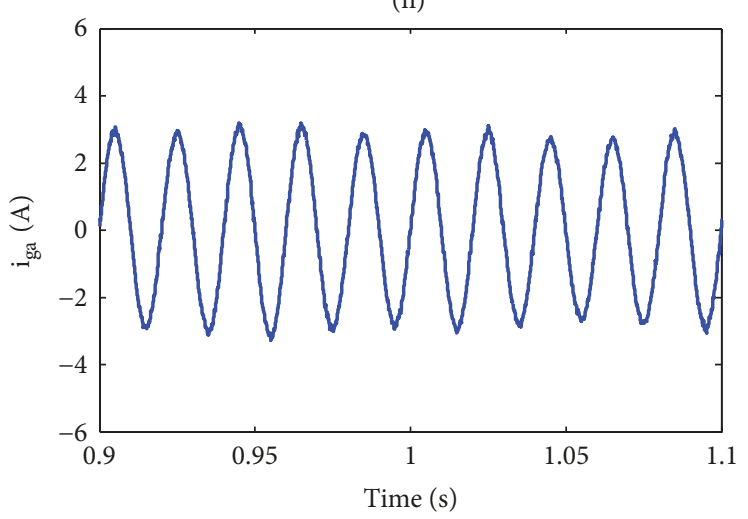

- RBF-NSMC

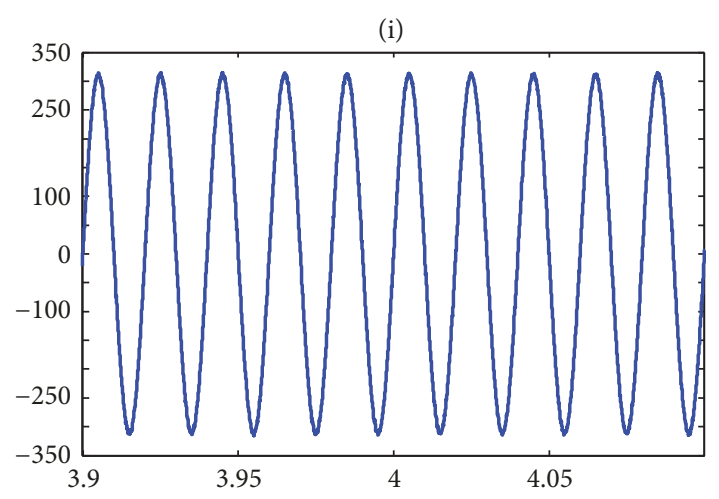

RBF-NSMC

(ii)

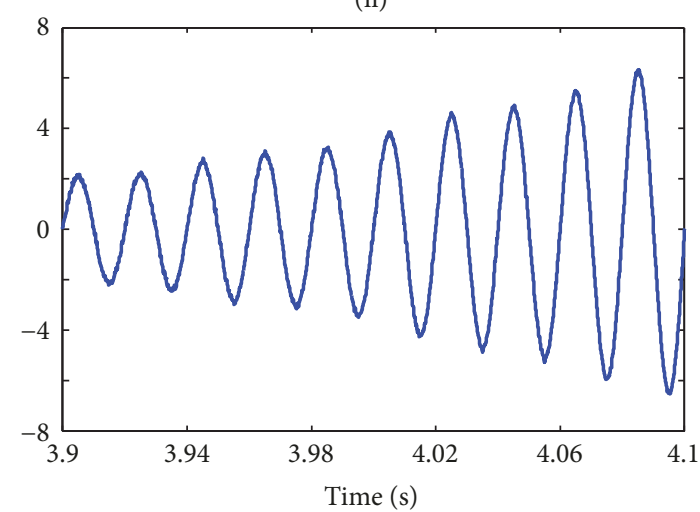

- RBF-NSMC

(a)

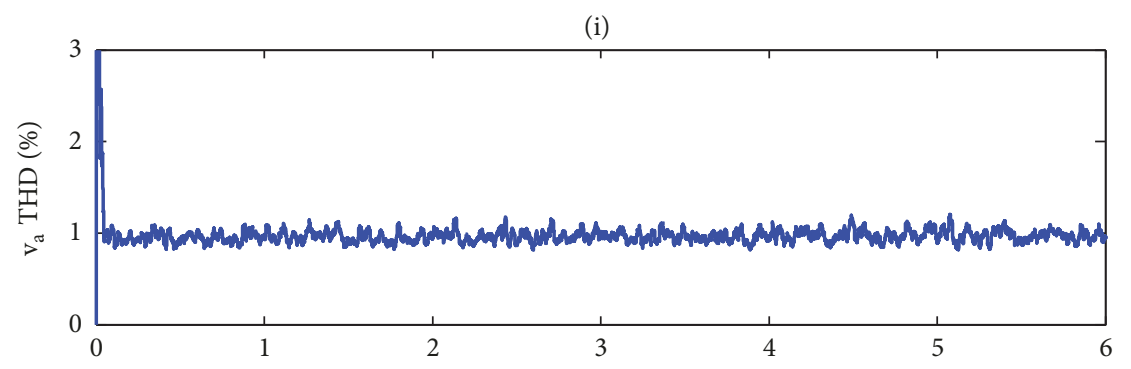

(ii)

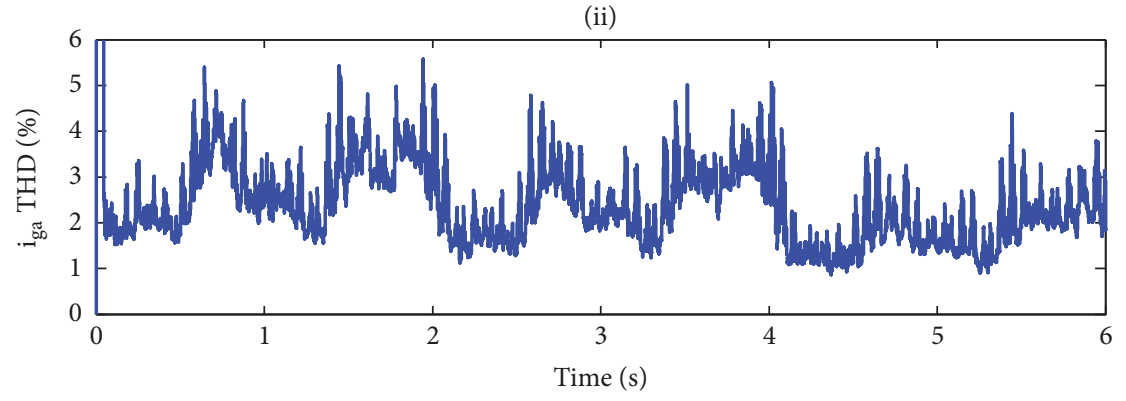

RBF-NSMC

(b)

FIGURE 12: Control system response to wind speed fluctuations with parameters uncertainties (at time $t=1 \mathrm{~s}$, variations of $+100 \%$ for $R_{s}$, $+50 \%$ for $L_{s},-20 \%$ for $\phi_{r}$, and $+30 \%$ for $J$ are introduced). (a) Zoom on LCL filter capacitor voltage and injected grid current trajectories with (b) corresponding THD behaviours. (i) Filter capacitor phase- $a$ voltage; (ii) injected grid phase- $a$ current. 
(i)

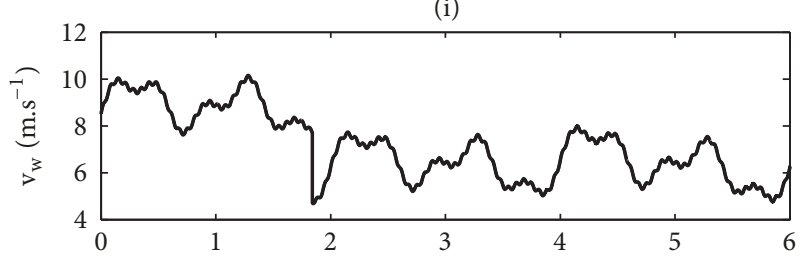

(ii)

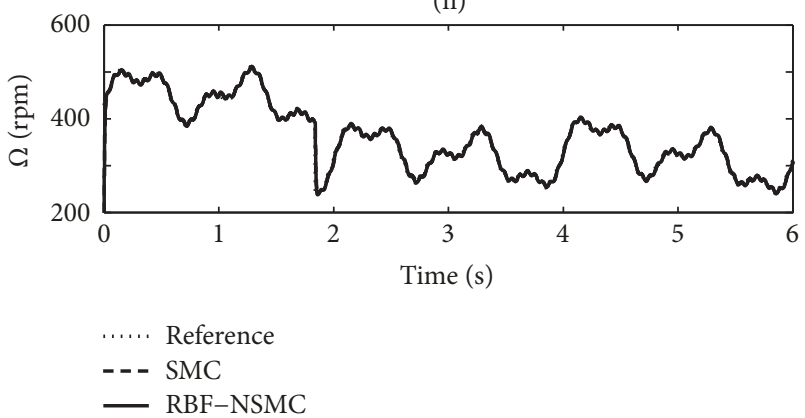

FIGURE 13: Control system response to wind speed fluctuations with parameters uncertainties and grid connected to standalone mode transition. The transition occurs at time $t=1.84 s$. (i) Wind profile with step change of $-3 \mathrm{~m} \cdot \mathrm{s}^{-1}$ at time $t=1.84 \mathrm{~s}$ and consequent (ii) rotor speed tracking response.

where $\tau_{i_{G}}^{c l}=L_{2} / K_{P i_{G}}$ is the closed loop time constant. The practical settling time with $5 \%$ criteria $\left(t_{s 5 \%}\right)$ of a first-order system is equal to three times its time constant. On the other hand the settling time of the closed loop system should be at least equal to the open loop settling time; that is,

$$
\begin{aligned}
t_{s 5 \%}^{c l} & \leq t_{s 5 \%}^{o l} \Longrightarrow \\
K_{P i_{G}} & \geq R_{2}
\end{aligned}
$$

Hence the outputs of the closed loop systems (A.1) and (A.3) will exponentially converge to their reference values if conditions (A.8) and (A.10) are satisfied. Thus the reference values of $d q$ components for the voltage across the LCL filter capacitor are expressed as

$$
\begin{aligned}
& v_{d}^{*}=K_{P i_{G d}} e_{i_{G d}}+K_{I i_{G d}} \int e_{i_{G d}} d t-L_{2} \omega_{g} i_{G q}+v_{g d} \\
& v_{q}^{*}=K_{P i_{G q}} e_{i_{G q}}+K_{I i_{G q}} \int e_{i_{G q}} d t+L_{2} \omega_{g} i_{G d}+v_{g q} .
\end{aligned}
$$

Adopt the same methodology for the GSC currents control loops and obtain

$$
\begin{aligned}
& v_{i d}^{*}=K_{P i_{i d}} e_{i d d}+K_{I i_{i d}} \int e_{i_{i d}} d t-L_{1} \omega_{g} i_{i q}+v_{d} \\
& v_{i q}^{*}=K_{P i_{i q}} e_{i_{i q}}+K_{I i_{i q}} \int e_{i_{i q}} d t+L_{1} \omega_{g} i_{i d}+v_{d}
\end{aligned}
$$

For the control design of the LCL filter capacitor voltage, rewrite (17) and (18) in the form of

$$
\begin{array}{ll}
C_{f} \dot{v}_{d}=i_{d}^{\prime}, & i_{d}^{\prime}=i_{i d}-i_{G d} \\
C_{f} \dot{v}_{q}=i_{q}^{\prime}, & i_{q}^{\prime}=i_{i q}-i_{G q} .
\end{array}
$$

The corresponding transfer functions are written as

$$
H_{v_{d}}^{o l}(s)=H_{v_{q}}^{o l}(s)=\frac{1}{C_{f} s}
$$

Let the correctors be

$$
\begin{aligned}
C_{v_{d}}(s) & =C_{v_{q}}(s)=K_{P v_{c}}+\frac{K_{I v_{c}}}{s}=\frac{K_{p v_{c}}\left(a_{v_{c}} s+1\right)}{a_{v_{c}} s}, \\
a_{v_{c}} & =\frac{K_{P v_{c}}}{K_{I v_{c}}}
\end{aligned}
$$

Then calculate the closed loop transfer functions and arrange them in the form of second-order systems as

$$
\begin{aligned}
H_{v_{d}}^{c l}(s) & =H_{v_{q}}^{c l}(s)=\frac{a_{v_{c}} s+1}{s^{2} / \omega_{0}^{2}+\left(2 \xi / \omega_{0}\right) s+1} \\
\text { with } a_{v_{c}} & =\frac{2 \xi}{\omega_{0}}, \\
K_{P v_{c}} & =a_{v_{c}} C_{f} \omega_{0}^{2} .
\end{aligned}
$$

$\xi$ and $\omega_{0}$ are, respectively, the system oscillation damping factor and undamped natural angular frequency. Thus the reference currents of the GSC are computed as

$$
\begin{aligned}
& i_{i d}^{*}=K_{P v_{d}} e_{v_{d}}+K_{I v_{d}} \int e_{v_{d}} d t+i_{i G d} \\
& i_{i q}^{*}=K_{P i_{q}} e_{v_{q}}+K_{I v_{q}} \int e_{v_{q}} d t+i_{i G q}
\end{aligned}
$$

\section{B. LCL Filter Design}

Grid side inverter rated power $P_{n}=5 K W$, nominal grid line to line voltage $U_{n}=220 \sqrt{3} \mathrm{~V}(\mathrm{rms})$, switching frequency $f_{s w}=5 \mathrm{KHz}$, and grid frequency $f_{g}=50 \mathrm{~Hz}$. In this study the calculation of LCL filter parameters is based on the methodology presented in [45].

Base Values Definition. The base impedance $Z_{b}$, inductance $L_{b}$, capacitance $C_{b}$, and nominal (rms) converter current are computed, respectively, as follows:

$$
\begin{aligned}
Z_{b} & =\frac{U_{n}^{2}}{P_{n}}, \\
L_{b} & =\frac{Z_{b}}{\omega_{n}}, \\
C_{b} & =\frac{1}{\omega_{n} Z_{b}} \\
\text { and } I_{n} & =\frac{P_{n}}{\sqrt{3} U_{n}}
\end{aligned}
$$

where $\omega_{n}=\omega_{g}=2 \pi f_{g}$ is the grid angular frequency. 
(i)

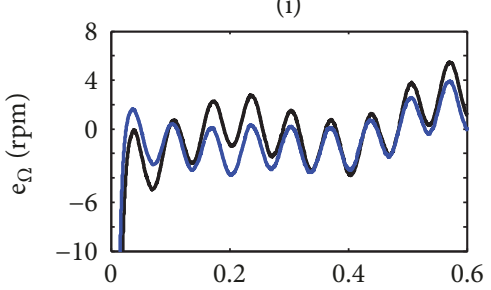

(ii)

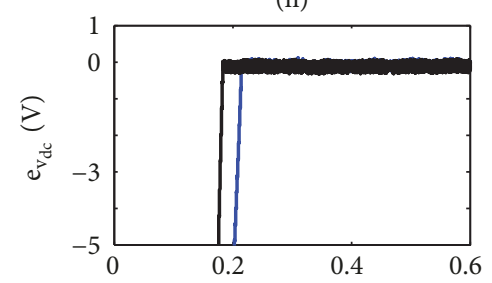

(iii)
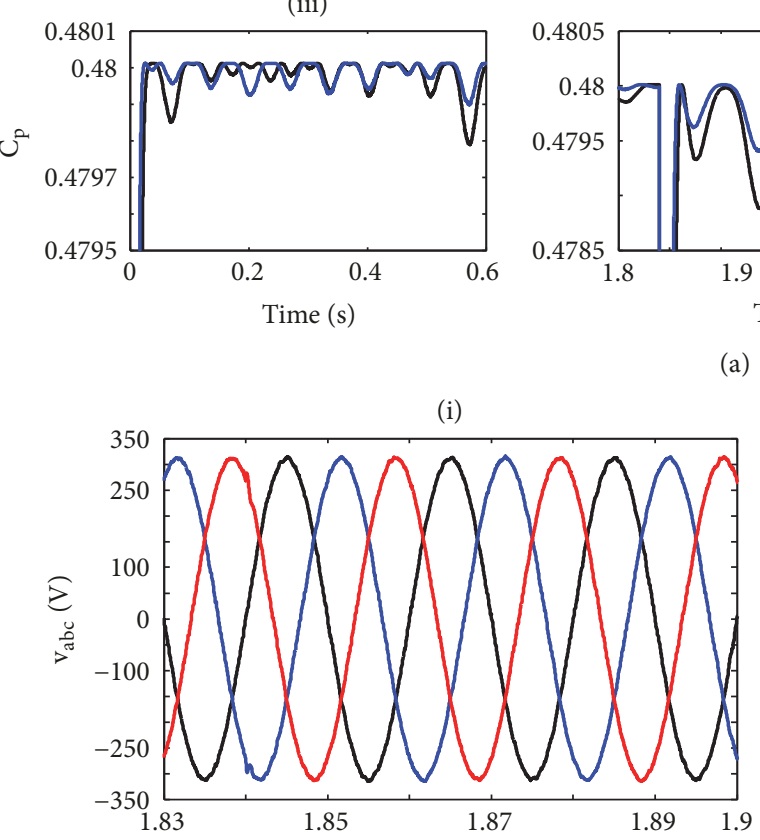

(ii)

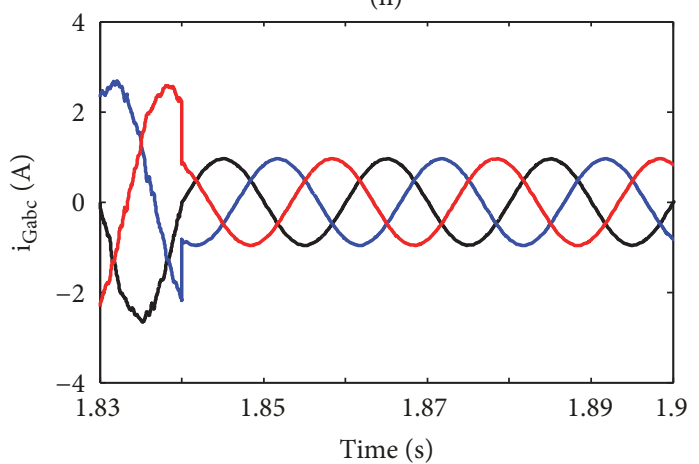

(i)

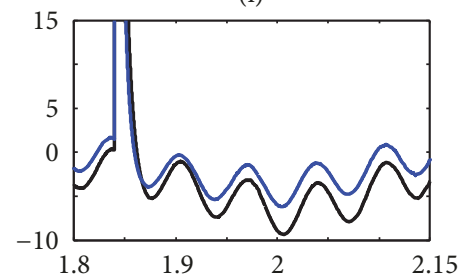

(ii)

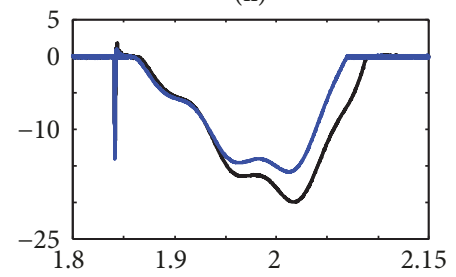

(iii)

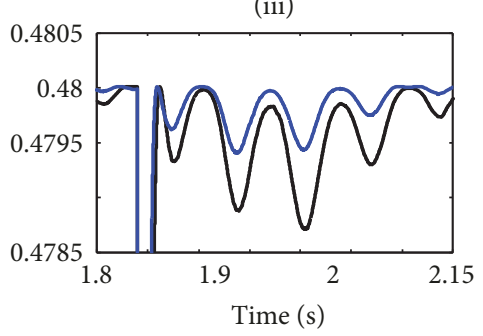

(a)

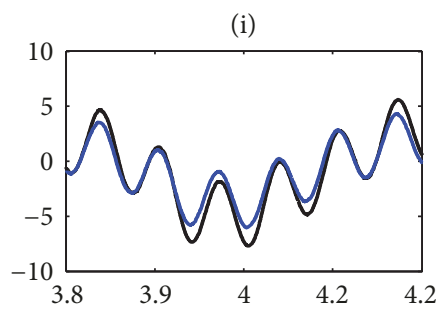

(ii)

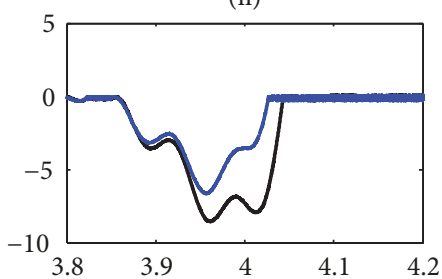

(iii)

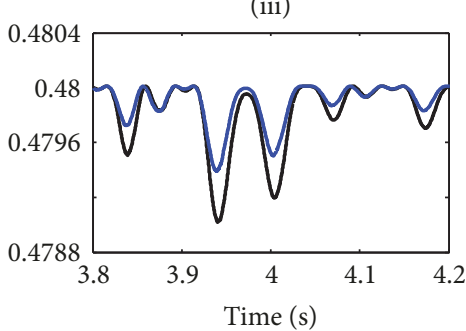

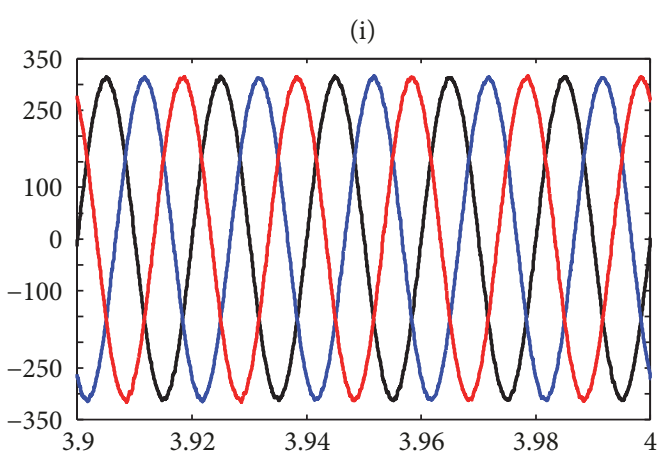

(ii)

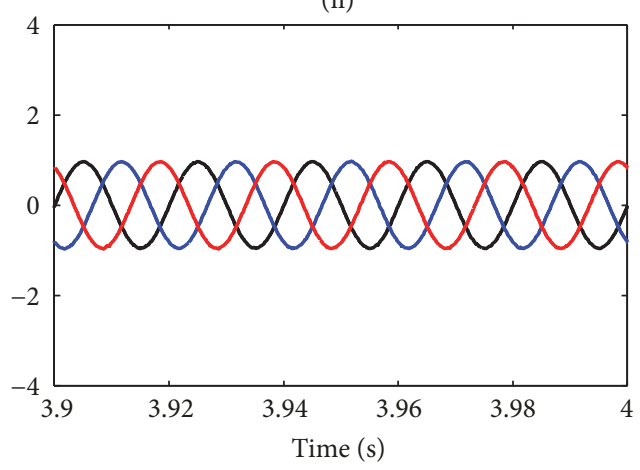

(b)

FigURE 14: Control system response to wind speed fluctuations with parameters uncertainties and grid connected to standalone mode transition. The transition occurs at time $t=1.84 \mathrm{~s}$. (a) Zoom on (blue line: RBF-NSMC, black line: SMC): (i) generator speed error, (ii) dc-link voltage error, and (iii) power coefficient. (b) Zoom on (proposed RBF-NSMC): (i) 3-phase voltage across the LCL filter capacitor; (ii) 3-phase total grid plus local load current. 
Converter Side Inductance $L_{1}$ Selection. The converter side inductance is chosen according to the following expression:

$$
L_{1} \geq \frac{v_{d c}^{*}}{6 f_{s w} I_{\text {maxrip }}} .
$$

where $I_{\text {maxrip }}$ is the maximum ripple current which must lie between $10 \%$ and $25 \%$ of the nominal converter current.

Filter Capacitance $C_{f}$ Selection. The filter capacitance should be less than $5 \%$ of the base value; i.e., $C_{f} \leq 0.05 C_{b}$.

Grid Side Inductance $L_{2}$ Selection. The grid inductance is selected as

$$
L_{2}=r_{a} L_{1} \quad \text { with } r_{a}=\left|\frac{1-H A}{H A\left(1-L_{1} C_{f} W_{s w}^{2}\right)}\right| .
$$

$r_{a}$ is the ratio between converter side and grid side inductances and $H A$ is the harmonics attenuation of the phase current. In this study the parameters have been chosen by considering $12 \%$ attenuation of maximum converter ripple current, $4.5 \%$ base capacitance, and $H A=0.05$. The resulting LCL filter parameters are $L_{1}=15.6 m H, C_{f}=5 \mu \mathrm{F}$, and $L_{2}=4 m H$. Thus the filter resonant frequency $f_{\text {res }}=$ $(1 / 2 \pi) \sqrt{\left(L_{1}+L_{2}\right) / L_{1} L_{2}}=1276 \mathrm{~Hz}$ is well between the desired range $10 f_{g}<f_{\text {res }}<0.5 f_{s w}$. The inductors internal resistances have been taken as $R_{1}=0.1 \Omega$ and $R_{2}=0.01 \Omega$.

\section{Data Availability}

The data used to support the findings of this study are included within the article.

\section{Conflicts of Interest}

There are no conflicts of interest.

\section{References}

[1] H. Sun, Y. Han, and L. Zhang, "Maximum Wind Power Tracking of Doubly Fed Wind Turbine System Based on Adaptive Gain Second-Order Sliding Mode," Journal of Control Science and Engineering, vol. 2018, Article ID 5342971, 11 pages, 2018.

[2] M. G. Zanchettin and R. Reginatto, "Grid integration limits for fixed-speed wind turbines with induction generators," Journal of Control, Automation and Electrical Systems, vol. 24, no. 6, pp. 873-884, 2013.

[3] F. Blaabjerg, Z. Chen, and S. B. Kjaer, "Power electronics as efficient interface in dispersed power generation systems," IEEE Transactions on Power Electronics, vol. 19, no. 5, pp. 1184-1194, 2004.

[4] J. A. Baroudi, V. Dinavahi, and A. M. Knight, "A review of power converter topologies for wind generators," Journal of Renewable Energy, vol. 32, no. 14, pp. 2369-2385, 2007.

[5] Z. Chen, J. M. Guerrero, and F. Blaabjerg, "A review of the state of the art of power electronics for wind turbines," IEEE Transactions on Power Electronics, vol. 24, no. 8, pp. 1859-1875, 2009.
[6] N. Goudarzi and W. D. Zhu, "A review on the development of wind turbine generators across the world," International Journal of Dynamics and Control, vol. 1, no. 2, pp. 192-202, 2013.

[7] M. M. Hossain and M. H. Ali, "Future research directions for the wind turbine generator system," Renewable \& Sustainable Energy Reviews, vol. 49, pp. 481-489, 2015.

[8] M. Chinchilla, S. Arnaltes, and J. C. Burgos, "Control of permanent-magnet generators applied to variable-speed windenergy systems connected to the grid," IEEE Transactions on Energy Conversion, vol. 21, no. 1, pp. 130-135, 2006.

[9] H. Geng and D. Xu, "Stability analysis and improvements for variable-speed multipole permanent magnet synchronous generator-based wind energy conversion system," IEEE Transactions on Sustainable Energy, vol. 2, no. 4, pp. 459-467, 2011.

[10] S. Li, T. A. Haskew, R. P. Swatloski, and W. Gathings, "Optimal and direct-current vector control of direct-driven PMSG wind turbines," IEEE Transactions on Power Electronics, vol. 27, no. 5, pp. 2335-2337, 2012.

[11] C. N. Wang, W. C. Lin, and X. K. Le, "Modelling of a pmsg wind turbine with autonomous control," Mathematical Problems in Engineering, Article ID 856173, p. 9, 2014.

[12] L. Fateh, O. Ahmed, O. Amar, D. Abdelhak, and B. Lakhdar, "Modeling and control of a permanent magnet synchronous generator dedicated to standalone wind energy conversion system," Frontiers in Energy, vol. 10, no. 2, pp. 155-163, 2016.

[13] M. F. M. Arani and Y. A.-R. I. Mohamed, "Assessment and Enhancement of a Full-Scale PMSG-Based Wind Power Generator Performance under Faults," IEEE Transactions on Energy Conversion, vol. 31, no. 2, pp. 728-739, 2016.

[14] E. Hamatwi, I. E. Davidson, and M. N. Gitau, "Rotor Speed Control of a Direct-Driven Permanent Magnet Synchronous Generator-Based Wind Turbine Using Phase-Lag Compensators to Optimize Wind Power Extraction," Journal of Control Science and Engineering, vol. 2017, Article ID 6375680, p. 17, 2017.

[15] B. Yang, T. Yu, H. Shu, X. Zhang, K. Qu, and L. Jiang, "Democratic joint operations algorithm for optimal power extraction of PMSG based wind energy conversion system," Energy Conversion and Management, vol. 159, pp. 312-326, 2018.

[16] M. S. Merzoug, H. Benalla, and L. Louze, "Nonlinear control of permanent magnet synchronous generators PMSG using feedback linearization," Revue des Energies Renouvelables, vol. 14, pp. 357-367, 2011.

[17] A. El Magri, F. Giri, G. Besançon, A. El Fadili, L. Dugard, and F. Z. Chaoui, "Sensorless adaptive output feedback control of wind energy systems with PMS generators," Control Engineering Practice, vol. 21, no. 4, pp. 530-543, 2013.

[18] S. Ciampichetti, M. L. Corradini, G. Ippoliti, and G. Orlando, "Sliding mode control of permanent Magnet Synchronous Generators for wind turbines," in Proceedings of the 37th Annual Conference of the IEEE Industrial Electronics Society, IECON '11, pp. 740-745, Australia, November 2011.

[19] S. Benelghali, M. E. Benbouzid, J. F. Charpentier, T. AhmedAli, and I. Munteanu, "Experimental Validation of a Marine Current Turbine Simulator: Application to a Permanent Magnet Synchronous Generator-Based System Second-Order Sliding Mode Control," IEEE Transactions on Industrial Electronics, vol. 58, no. 1, pp. 118-126, 2011.

[20] M. S. Merzoug, H. Benalla, and L. Louze, "Sliding mode control (SMC) of permanent magnet synchronous generators (PMSG)," in Proceedings of the Terragreen: Clean Energy Solutions for Sustainable Environment, CESSE '12, pp. 43-52, Lebanon, February 2012. 
[21] S. Li-Xia, W. Zhe, H. Feng-Ling, and Y. Feng, "A chattering-free terminal sliding mode control of direct-drive PWM forwind generation system," in Proceedings of the IEEE IECON, 4th Annual IEEE International Conference on Cyber Technology in Automation, pp. 296-301, 2014.

[22] S. Shoja-Majidabad, H. Toosian-Shandiz, and A. Hajizadeh, "Robust fractional-order control of PMSG-based WECS," International Journal of Automation and Control Engineering, vol. 9, no. 2, pp. 107-129, 2015.

[23] Y. Errami, M. Ouassaid, and M. Maaroufi, "Design of variable structure control for wind energy system-based permanent magnet synchronous generator and operating under different grid conditions," International Journal of Systems, Control and Communications, vol. 7, no. 2, pp. 164-185, 2016.

[24] G. Kenne, R. M. Douanla, and F. B. Pelap, "An adaptive nonlinear control strategy for a stand-alone permanent magnet synchronous generator driven by a variable speed wind turbine," International Journal of Dynamics and Control, vol. 5, no. 4, pp. 1103-1113, 2017.

[25] Y. Errami, A. Obbadi, S. Sahnoun, M. Ouassaid, and M. Maaroufi, "Power Extraction Control of Variable Speed Wind Turbine Systems Based on Direct Drive Synchronous Generator in All Operating Regimes," Journal of Electrical and Computer Engineering, vol. 2018, Article ID 3837959, 17 pages, 2018.

[26] B. Yang, T. Yu, H. Shu et al., "Passivity-based sliding-mode control design for optimal power extraction of a PMSG based variable speed wind turbine," Journal of Renewable Energy, vol. 119, pp. 577-589, 2018.

[27] M. A. Mayosky and G. I. E. Cancelo, "Direct adaptive control of wind energy conversion systems using Gaussian networks," IEEE Transactions on Neural Networks and Learning Systems, vol. 10, no. 4, pp. 898-906, 1999.

[28] L. Jinkun, Radial Basis Function Neural Network Control for Mechanical Systems, Tsinghua University Press, Beijing, China, 2013.

[29] C. C. Hua, C. X. Yu, and X. P. Guan, "Neural network observerbased networked control for a class of nonlinear systems," Neurocomputing, vol. 133, pp. 103-110, 2014.

[30] G. Kenné, A. S. Fotso, and F. Lamnabhi-Lagarrigue, "A new adaptive control strategy for a class of nonlinear system using rbf neuro-sliding-mode technique: application to SEIG wind turbine control system," International Journal of Control, vol. 90, p. 18, 2017.

[31] C.-H. Lin, "Recurrent modified Elman neural network control of permanent magnet synchronous generator system based on wind turbine emulator," Journal of Renewable and Sustainable Energy, vol. 5, no. 5, 2013.

[32] C.-H. Lin, "Dynamic control for permanent magnet synchronous generator system using novel modified recurrent wavelet neural network," Nonlinear Dynamics, vol. 77, no. 4, pp. 1261-1284, 2014.

[33] C.-M. Hong, C.-H. Chen, and C.-S. Tu, "Maximum power point tracking-based control algorithm for PMSG wind generation system without mechanical sensors," Energy Conversion and Management, vol. 69, pp. 58-67, 2013.

[34] S. Boulouma and H. Belmili, "RBF neural network sliding mode control of a PMSG based wind energy conversion system," in Proceedings of the International Renewable and Sustainable Energy Conference, IRSEC '16, pp. 438-443, Morocco, November 2016.
[35] A. Barra, H. Ouadi, F. Giri, and R. Chakib, "Sensorless Nonlinear Control of Wind Energy Systems with Doubly Fed Induction Generator," Journal of Control, Automation and Electrical Systems, vol. 27, no. 5, pp. 562-578, 2016.

[36] S. Ghoudelbourk, D. Dib, A. Omeiri, and A. T. Azar, "MPPT control in wind energy conversion systems and the application of fractional control (PI $\alpha$ ) in pitch wind turbine," International Journal of Modelling, Identification and Control, vol. 26, no. 2, pp. 140-151, 2016.

[37] F. Jaramillo-Lopez, G. Kenne, and F. Lamnabhi-Lagarrigue, "Maximum power extraction on wind turbine systems using block-backstepping with gradient dynamics control," International Journal of Adaptive Control and Signal Processing, vol. 31, no. 6, pp. 835-858, 2017.

[38] J. S. Thongam, P. Bouchard, R. Beguenane, A. F. Okou, and A. Merabet, "Control of variable speed wind energy conversion system using a wind speed sensorless optimum speed MPPT control method," in Proceedings of the 37th Annual Conference of the IEEE Industrial Electronics Society, IECON '11, pp. 855860, Australia, November 2011.

[39] S. A. Deraz and F. E. Abdel Kader, "A new control strategy for a stand-alone self-excited induction generator driven by a variable speed wind turbine," Journal of Renewable Energy, vol. 51, pp. 263-273, 2013.

[40] F. Jaramillo-Lopez, G. Kenne, and F. Lamnabhi-Lagarrigue, "A novel online training neural network-based algorithm for wind speed estimation and adaptive control of PMSG wind turbine system for maximum power extraction," Journal of Renewable Energy, vol. 86, pp. 38-48, 2016.

[41] N. Pogaku, M. Prodanović, and T. C. Green, "Modeling, analysis and testing of autonomous operation of an inverter-based microgrid," IEEE Transactions on Power Electronics, vol. 22, no. 2, pp. 613-625, 2007.

[42] T. Ahmed-Ali, G. Kenné, and F. Lamnabhi-Lagarrigue, "Identification of nonlinear systems with time-varying parameters using a sliding-neural network observer," Neurocomputing, vol. 72, no. 7-9, pp. 1611-1620, 2009.

[43] V. I. Utkin, "Sliding mode control: mathematical tools, design and applications," in Nonlinear and optimal control theory, vol. 1932 of Lecture Notes in Math., pp. 289-347, Springer, Berlin, 2008.

[44] F. Mancilla-David and R. Ortega, "Adaptive passivity-based control for maximum power extraction of stand-alone windmill systems," Control Engineering Practice, vol. 20, no. 2, pp. 173-181, 2012.

[45] T. Orlowska-Kowalska, F. Blaabjerg, and J. Rodriguez, Advanced and intelligent control in power electronics and drives, Springer, Heidelberg, 2014. 


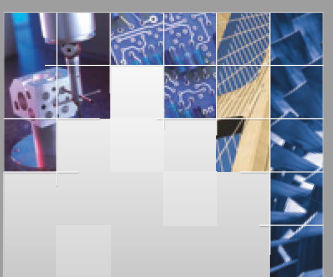

\section{Enfincering}
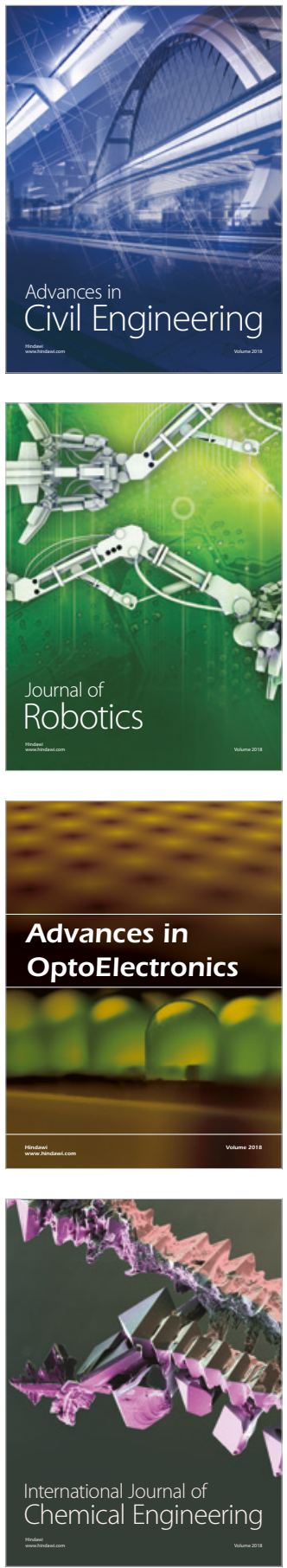

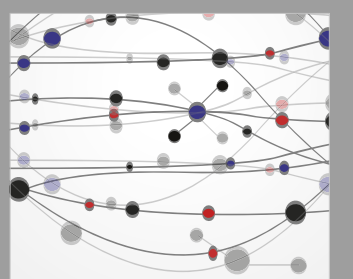

\section{Rotating \\ Machinery}

The Scientific World Journal

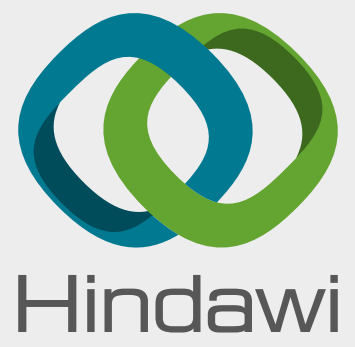

Submit your manuscripts at

www.hindawi.com
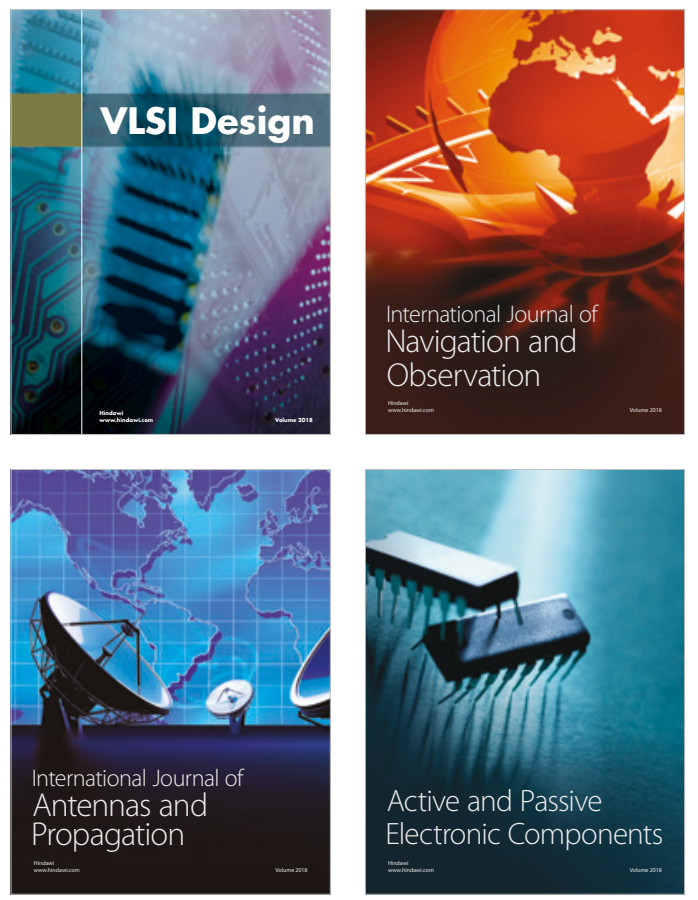
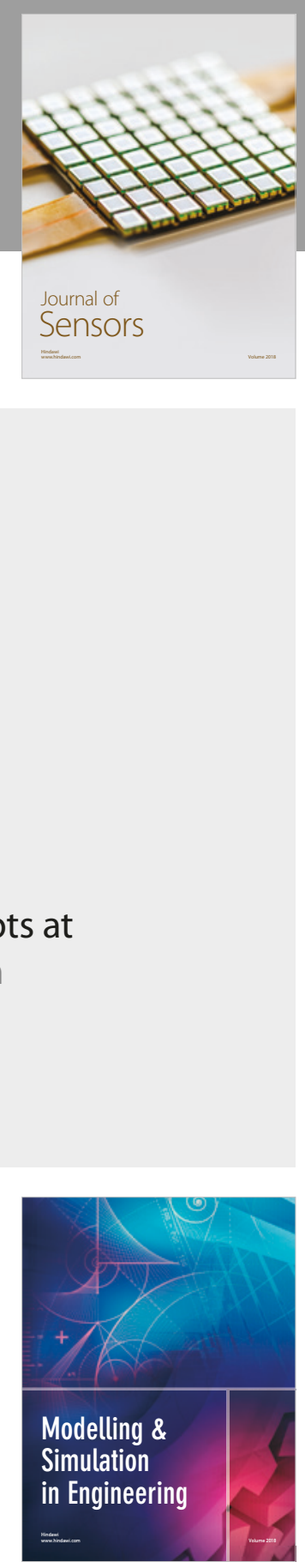

\section{Advances \\ Multimedia}
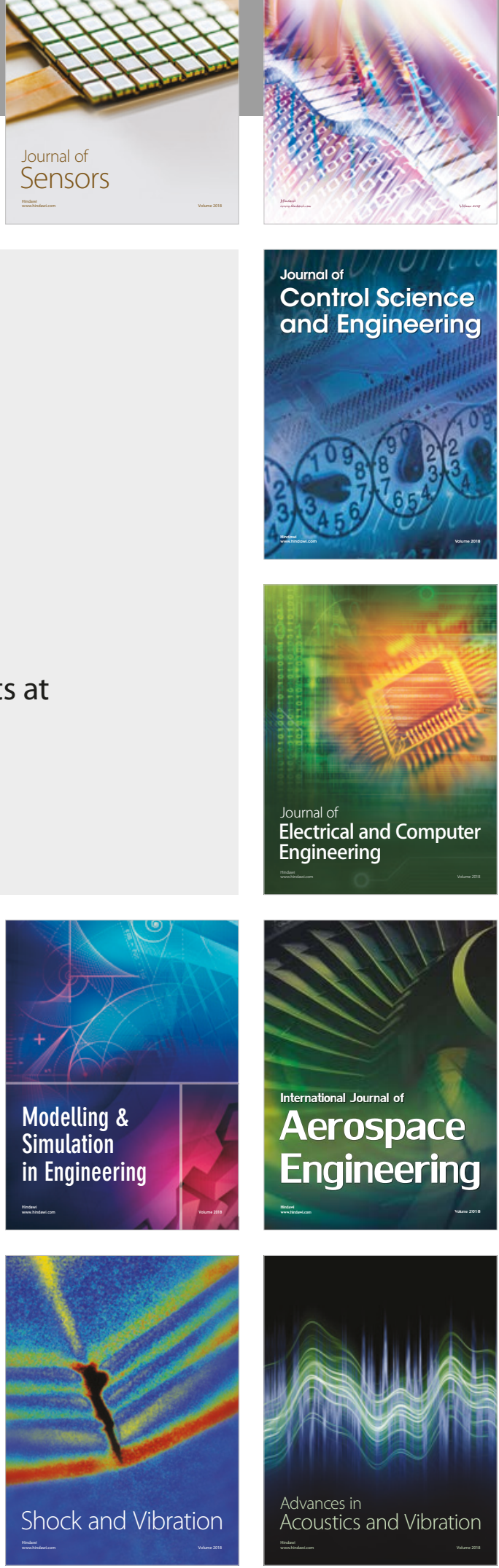